
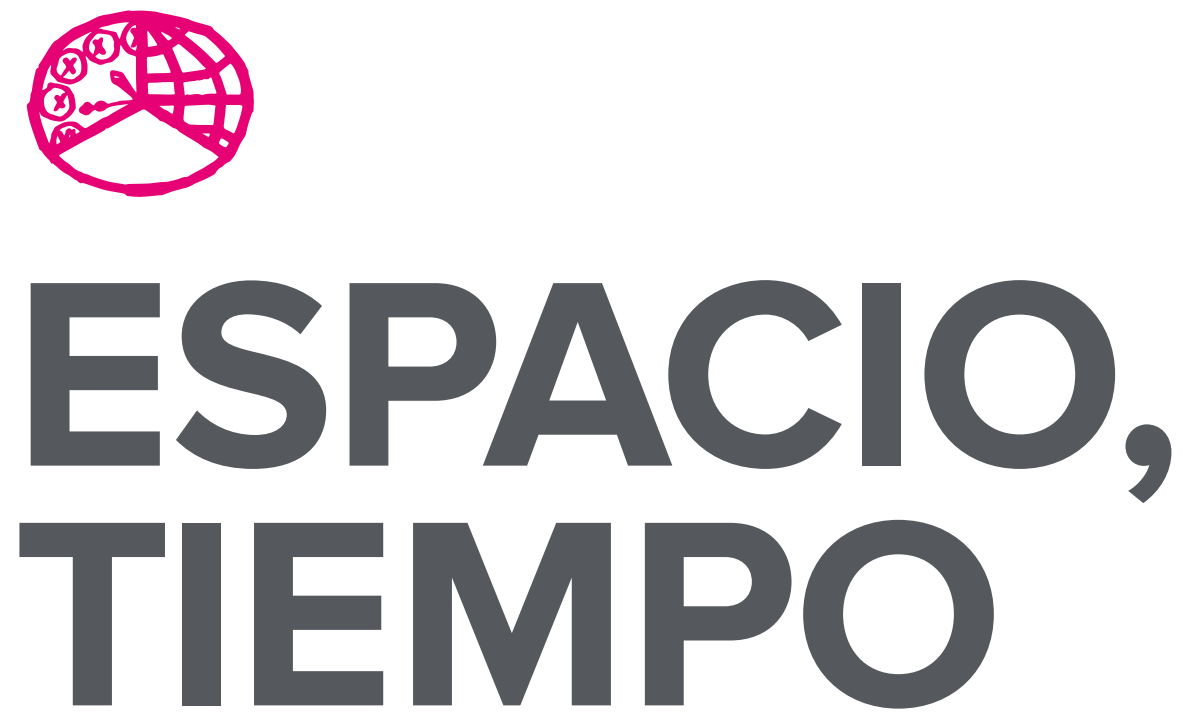

AÑO 2020

ISSN 1131-7698

E-ISSN 2340-1354
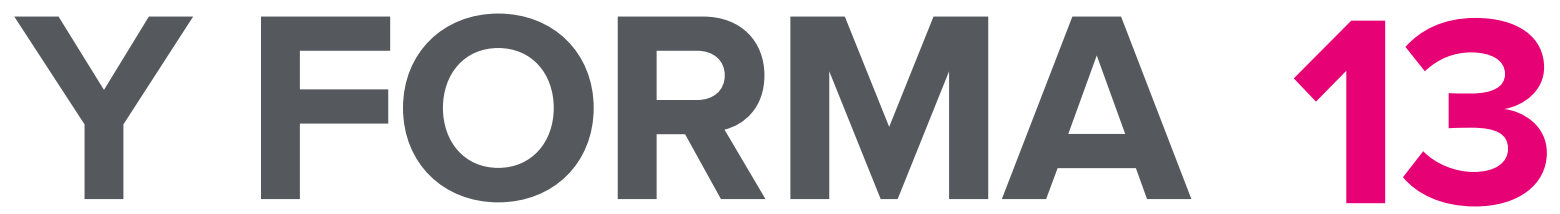

SERIE I PREHISTORIA Y ARQUEOLOGÍA

REVISTA DE LA FACULTAD DE GEOGRAFÍA E HISTORIA 


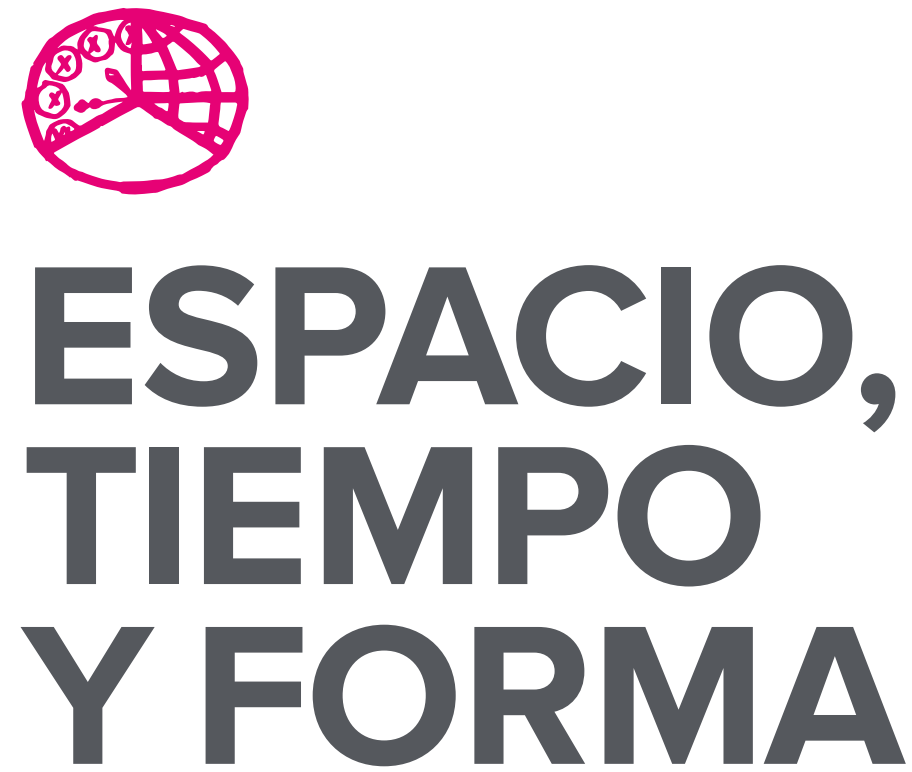

AÑO 2020

ISSN 1131-7698

E-ISSN 2340-1354

SERIE I PREHISTORIA Y ARQUEOLOGÍA

REVISTA DE LA FACULTAD DE GEOGRAFİA E HISTORIA

DOI: http://dx.doi.org/10.5944/etfi.13.2020

\section{UกED}

UNIVERSIDAD NACIONAL DE EDUCACIÓN A DISTANCIA 
La revista Espacio, Tiempo y Forma (siglas recomendadas: ETF), de la Facultad de Geografía e Historia de la UNED, que inició su publicación el año 1988, está organizada de la siguiente forma:

$$
\begin{aligned}
& \text { SERIE I - Prehistoria y Arqueología } \\
& \text { SERIE II - Historia Antigua } \\
& \text { SERIE III - Historia Medieval } \\
& \text { SERIE IV - Historia Moderna } \\
& \text { SERIE V - Historia Contemporánea } \\
& \text { SERIE VI - Geografía } \\
& \text { SERIE VII - Historia del Arte }
\end{aligned}
$$

Excepcionalmente, algunos volúmenes del año 1988 atienden a la siguiente numeración:

$$
\begin{aligned}
& \mathrm{N} .^{\circ} 1 \text { - Historia Contemporánea } \\
& \mathrm{N}^{\circ} 2 \text { - Historia del Arte } \\
& \mathrm{N} .^{\circ} 3 \text { - Geografía } \\
& \mathrm{N} .^{\circ} 4 \text { - Historia Moderna }
\end{aligned}
$$

ETF no se solidariza necesariamente con las opiniones expresadas por los autores.

\author{
UNIVERSIDAD NACIONAL DE EDUCACIÓN A DISTANCIA \\ Madrid, 2020 \\ SERIE I PREHISTORIA Y ARQUEOLOGÍA N. ${ }^{0} 13,2020$ \\ ISSN 1131-7698 · E-ISSN 2340-1354 \\ DEPÓSITO LEGAL \\ M-21.037-1988 \\ URL \\ ETF I PREHISTORIA Y ARQUEOLOGÍA · http://revistas.uned.es/index.php/ETFI/index \\ DISEÑO Y COMPOSICIÓN \\ Carmen Chincoa Gallardo \\ http://www.laurisilva.net/cch \\ Impreso en España · Printed in Spain
}

(c) (i) () Esta obra está bajo una licencia Creative Commons

Reconocimiento-NoComercial 4.0 Internacional. 


\section{ARTÍCULOS · ARTICLES}





\title{
LUGAR DE PASO, MEMORIAS ANTIGUAS. EL YACIMIENTO DEL ARROYO DE LAS ALMAS (LA FREGENEDA, SALAMANCA) Y SU ARTE RUPESTRE PALEOLÍTICO AL AIRE LIBRE
}

\author{
PLACE OF PASSAGE, ANCIENT MEMORIES. \\ THE SITE OF ARROYO DE LAS ALMAS \\ (LA FREGENEDA, SALAMANCA) AND ITS \\ OPEN-AIR PALAEOLITHIC ROCK ART
}

\author{
Mário Reis y Carlos Vázquez Marcos² \\ Recibido: 07/02/2020 - Aceptado: 25/11/2020 \\ DOI: http://dx.doi.org/10.5944/etfi.13.2020.2669o
}

\begin{abstract}
Resumen
El yacimiento rupestre al aire libre del Arroyo de las Almas, en las inmediaciones del encuentro entre los ríos Águeda y Duero, presenta un conjunto de 600 motivos grabados, con una larga diacronía desde el Paleolítico Superior hasta la Edad Contemporánea. Presentamos una visión detallada de su arte Paleolítico, con 2I figuras documentadas en 5 rocas, grabadas por incisión, y que corresponden a I3 zoomorfos, 7 signos y I motivo indeterminable, además de grupos de líneas no figurativas. Los análisis formales y técnicos llevados a cabo y sus paralelos, nos permiten afirmar que son integrables, desde la óptica cronocultural, entre el inicio del Magdaleniense y el final del ciclo artístico Paleolítico. Este conjunto, formaría parte de la vasta red de yacimientos artísticos en la cuenca del Duero, en su mayoría con arte al aire libre, cuyas principales características de implantación sugieren una inicial función como lugar privilegiado de paso, entorno a la desembocadura de Águeda.
\end{abstract}

Palabras clave

Arte rupestre; Paleolítico Superior; Tardiglaciar; Magdaleniense; Cuenca del Duero; Grabados; Incisión.

1. Centro de Estudos em Arqueologia, Artes e Ciências do Património da Universidade de Coimbra (CEAACP) / Fundação Côa Parque (Portugal).Rua Alto do Golim, 5, 5150-701 Vila Nova de Foz Côa, Portugal; $<$ marioreissoares@sapo.pt>.

2. Grupo de Investigación Reconocido (GIR) PREHUSAL / Centro de Estudios Mirobrigenses (CEM). Departamento de Prehistoria, Ha. Antigua y Arqueología. Facultad de Geografía e Historia. Universidad de Salamanca; <carlosvazquezmarcos@gmail.com>. 


\begin{abstract}
The open-air rock art site Arroyo de las Almas, close to the meeting point of the rivers Águeda and Douro, displays approximately 600 engraved motifs, with a chronology ranging from the Upper Palaeolithic to Contemporary Age. We present a detailed analysis of the Upper Palaeolithic art of the site, corresponding to 2I registered figures in 5 rocks, all engraved by incision and corresponding to 13 zoomorphic figures, 7 signs and I undetermined motif, as well as groups of non-figurative lines. The typological and stylistic analyses carried out and their parallels allow us to affirm that all of them are chronologically integrable between the beginning of the Magdalenian and the end of the Palaeolithic artistic cycle. This set was part of the vast network of artistic sites in the Douro basin, for the most part with openair art. The main implantation characteristics of the site suggest its function as a privileged passage site, around the mouth of the Águeda.
\end{abstract}

\title{
Keywords
}

Rock art; Upper Palaeolithic; Lateglacial; Magdalenian; Douro Basin; Engraving; Incision. 


\section{INTRODUCCIÓN}

Este conjunto rupestre con grabados al aire libre destaca tanto por el importante número de rocas y figuras con manifestaciones artísticas inventariadas, 24 y 600 respectivamente, como por su dilatado abanico cronológico, que va desde el Paleolítico Superior hasta la Época Contemporánea, transitando por la Prehistoria Reciente y la Edad de Hierro.

El yacimiento fue dado a conocer en una sucinta aportación preliminar tras los primeros hallazgos acaecidos en septiembre de 2015 (Reis \& Vázquez Marcos 2015). Posteriormente, se elaboró un segundo texto donde, de forma genérica, se describieron las principales características de su arte rupestre en todo su asincronismo, además de abordar el entorno físico y paisajístico en el que se insertan estas rocas decoradas (Reis \& Vázquez Marcos 2019), queriendo completar, con este texto más amplio y detallado, la precedente breve nota sobre las figuras más antiguas del conjunto gráfico, las del Paleolítico Superior (Vázquez Marcos \& Reis 2019).

Los motivos superopaleolíticos han sido agrupados en tres categorías temáticas diferentes: I3 figuras zoomorfas, 7 signos y I motivo indeterminable, además de un variado conjunto no figurativo compuesto por trazos aislados o conjuntos de trazos aparentemente inconexos. Una categoría que podría ser ampliada debido a la elevada dificultad, en algunas de las rocas inventariadas, para diferenciar, de forma indubitable, los trazos paleolíticos de aquellos otros más recientes. Todas estas figuras y grupos de motivos no figurativos documentados, ejecutados mediante la técnica de grabado inciso, fueron localizadas por los autores de este artículo en 5 afloramientos rocosos de pizarras y esquistos.

Estos nuevos descubrimientos gráficos convierten el enclave rupestre del Arroyo de las Almas, tanto por su situación en el ámbito geográfico de la submeseta norte peninsular como por sus características formales, tipo de soporte, cronología, ambiente y estado de conservación, no solo en el segundo enclave con arte rupestre Paleolítico más relevante en la provincia de Salamanca, tras el sitio arqueológico de Siega Verde (Serranillo, Salamanca) (Alcolea \& Balbín 2006, 2008; Bueno et al. 2008; Fernández Moreno \& Baptista 20I0; Vázquez Marcos 2014, 2015, 2017, 2018, 2019; Vázquez Marcos \& Angulo Cuesta 20I9), sino en uno de los más reseñables del territorio autonómico y peninsular (Reis \& Vázquez Marcos 2019).

En el marco de la temática del Paleolítico Superior abordada, este nuevo sitio entronca con la tendencia de nuevos descubrimientos artísticos al aire libre, tanto en la península ibérica como en el resto del continente europeo (Welker 2016), de entre los que destaca, por encima de otros territorios, el gran grupo regional de arte Paleolítico al aire libre de la cuenca del Duero, en el que se inserta el Arroyo de las Almas (Balbín 2008; Baptista 1999, 2009, 2012; Figueiredo et al. 2014, 2016; Garate et al. 2016; Reis 2012, 2013, 2014; Santos 2012, 20I7; Santos et al. 2015; Vázquez Marcos \& Angulo Cuesta 2019). 


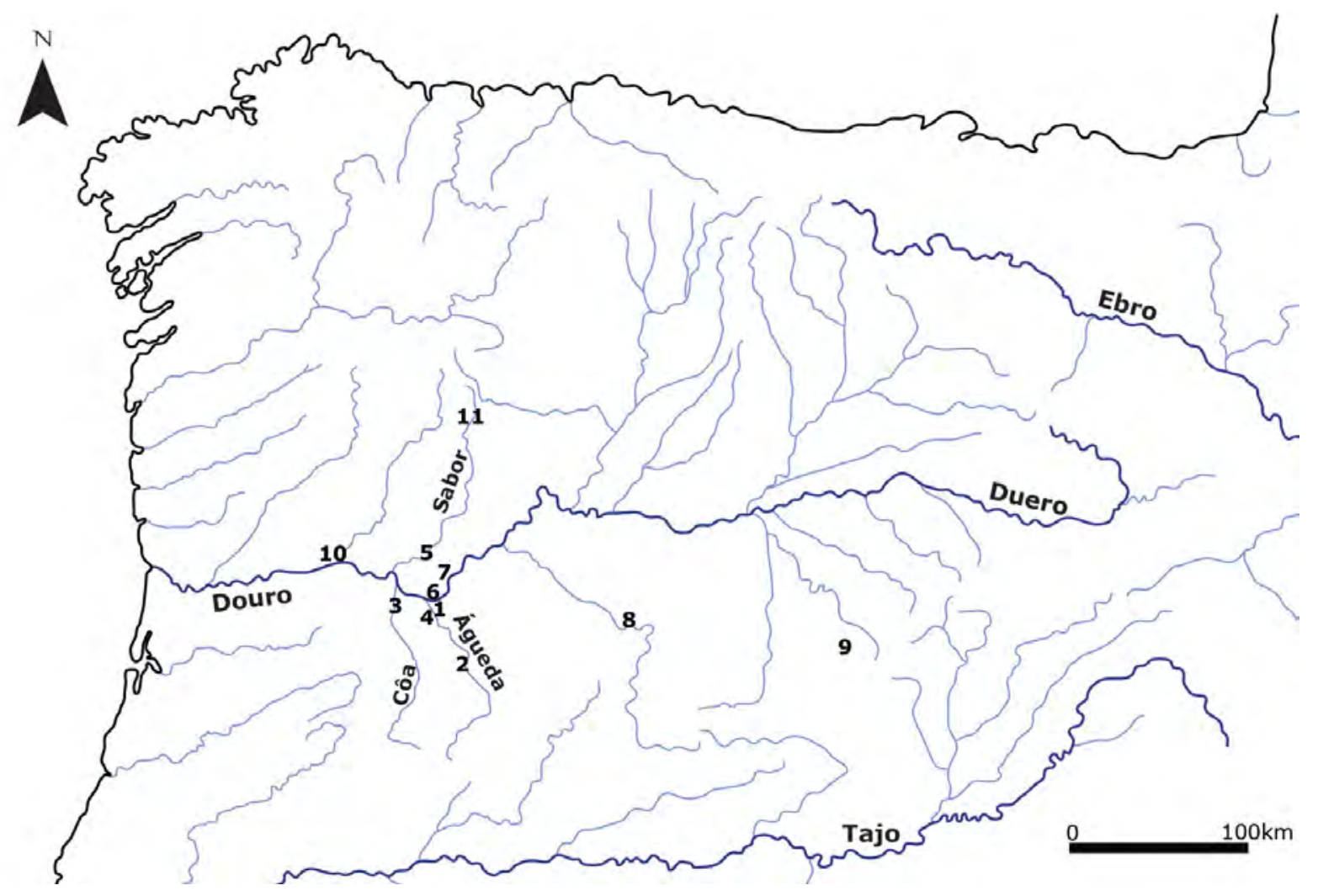

FIGURA 1. MAPA EN EL QUE SE INDICA LA CUENCA DEL DUERO Y SE INDIVIDUALIZAN LOS SITIOS O CONJUNTOS DE SITIOS CON ARTE PALEOLÍTICO AL AIRE LIBRE MENCIONADOS EN EL TEXTO: 1 - ARROYO DE LAS ALMAS; 2 - SIEGA VERDE; 3 - CONIUNTO DEL ARTE DEL CÔA; 4 - REDOR DO PORCO; 5 - BAJO SABOR (MEDAL, RIBEIRA DA SARDINHA Y PEDRA DE ASMA); 6 - FRAGA DO GATO; 7 - MAZOUCO; 8 - LA SALUD; 9 - CONJUNTO DE DOMINGO GARCÍA; 10 - FOZ DO TUA; 11 - ALTO SABOR (SAMPAIO, POUSADOURO Y FRAGA ESCREVIDA)

Está claro, por tanto, que Arroyo de las Almas no es un sitio aislado, al emplazarse en la vasta red de enclaves con arte Paleolítico al aire libre que conocemos a lo largo del valle del Duero y que incluye lugares cercanos y alejados, como el conjunto de Domingo García (Segovia) (Balbín 2008: 23-25; Ripoll \& Municio I999; Rivero et al. 20I8), el yacimiento de La Salud, en el río Tormes (Salamanca) (Garate et al. 20I6), o los yacimientos portugueses de Mazouco y de los ríos Tua y Sabor (Baptista 2009; Figueiredo et al. 2014, 2016; Santos 2017; Teixeira \& Sanches 2017) con los que existen, en algunos casos, irrefutables paralelos formales, técnicos y cronoculturales (Figura 2).

Los más cercanos, además de Siega Verde, son la roca de Redor do Porco, a poco más de $2 \mathrm{~km}$ del sitio protagonista de este trabajo, con una sensacional representación de un uro premagdaleniense, y ejecutada mediante un profundo grabado piqueteado, en la margen izquierda del río Águeda (Baptista \& Reis 20II), o el sitio rupestre con pinturas paleolíticas al aire libre de Fraga do Gato (Baptista 2009: 226-229), en la Ribeira do Mosteiro (Poiares, Freixo de Espada à Cinta), margen portuguesa del río Duero, a menos de $5 \mathrm{~km}$ en línea recta del Arroyo de las Almas. Asimismo, y aunque este nuevo yacimiento está claramente separado de la región 
artística del valle del Côa, la distancia, con respecto de las rocas paleolíticas más cercanas es exigua, poco más de $8 \mathrm{~km}$ en línea recta, que asciende a $18 \mathrm{~km}$ si tenemos en cuenta la desembocadura del río Côa en el Duero, punto neurálgico de este inmenso complejo rupestre al aire libre (Baptista I999, 2009, 2012; Reis 2012, 2013, 20I4; Santos 20I7). A pesar de esta proximidad, ninguna de las rocas paleolíticas del Arroyo de las Almas tiene contacto visual directo con los citados enclaves, ya que están encerradas en el fondo del valle, con localizaciones que impiden la visibilidad entre ellas. Esta amplitud visual se gana, sin embargo, con facilidad. Únicamente se ha de salir del fondo del valle para que se haga perceptible dicho entorno, mostrando la indiscutible relación paisajística existente entre todos estos lugares arqueológicos.

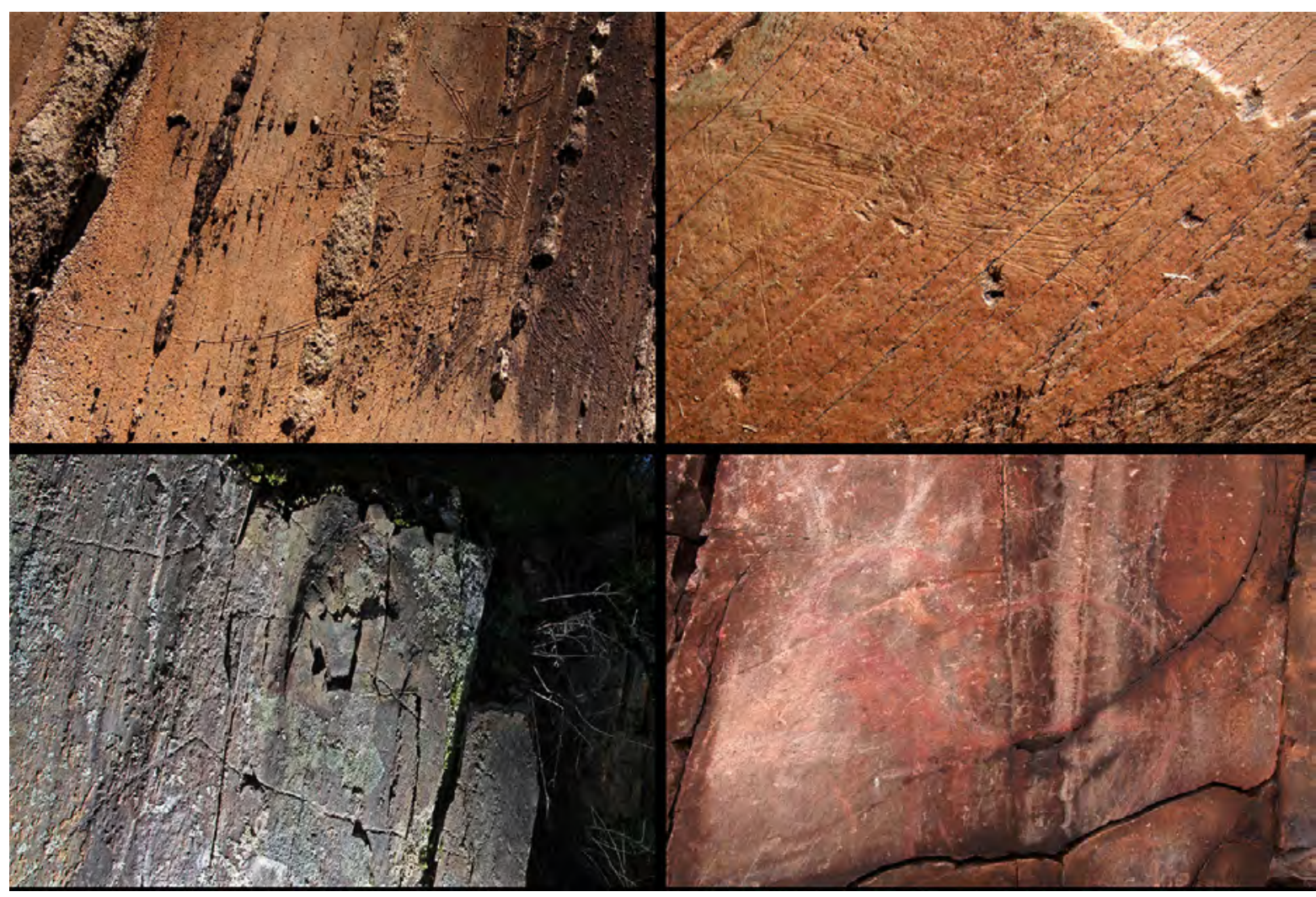

FIGURA 2. ALGUNOS EJEMPLOS DE ARTE RUPESTRE PALEOLITICO EN LAS CERCANÍAS DEL ARROYO DE LAS ALMAS. ARRIBA, A LA IZQUIERDA, CIERVO Y CABALLO INCISOS SITUADOS EN LA ROCA IO DE PENASCOSA (VALLE DEL CÔA). ARRIBA, A LA DERECHA, CIERVA INCISA DOCUMENTADA EN SIEGA VERDE. ABAJO, A LA IZQUIERDA, DETALLE DE LA CABEZA DEL URO PIQUETEADO DE REDOR DO PORCO. ABAJO, A LA DERECHA, DOS ANIMALES PINTADOS DE FRAGA DO GATO

\section{IMPLANTACIÓN DE LAS ROCAS CON MOTIVOS GRABADOS PALEOLIITICOS: UNA VISIÓN DE CONJUNTO}

Como ya indicamos, hemos descrito íntegramente en otra publicación, y de forma detallada, la distribución de las 24 rocas decoradas del conjunto de Arroyo de las Almas, independientemente del período cronológico al que han sido adscritas sus figuras (Reis \& Vázquez Marcos 20I9). Entretanto, abordaremos aquí la implantación 
de las 5 rocas inventariadas con grabados paleolíticos. Estas, se encuentran en tres de los cuatro núcleos del Arroyo del las Almas, estando ausentes en el segundo de los núcleos (Figura 3).

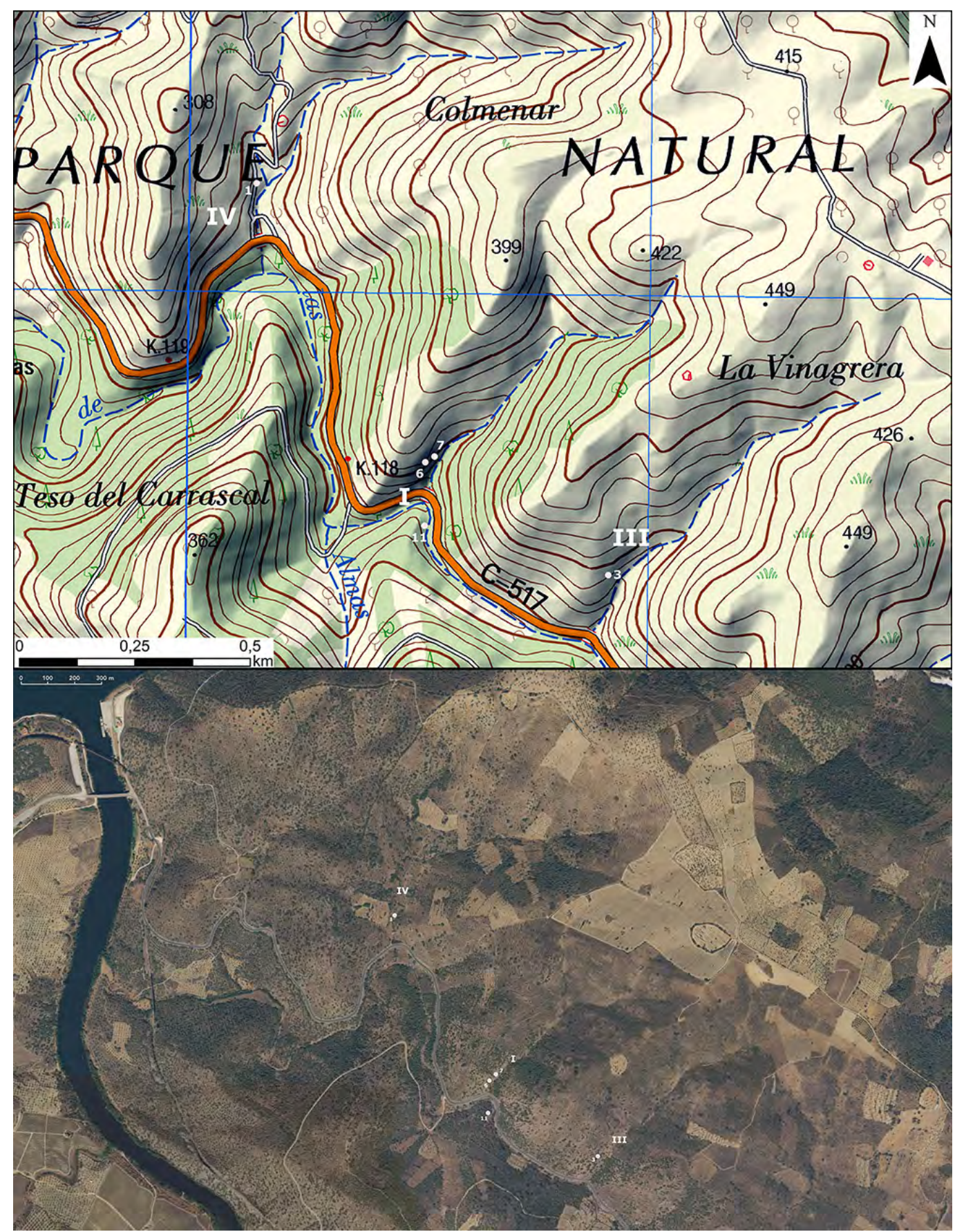

FIGURA 3. ARRIBA, LA UBICACIÓN CARTOGRÁFICA DE LAS CINCO ROCAS PALEOLÍTICAS DEL ARROYO DE LAS ALMAS, INDICANDO EL NÚCLEO AL QUE PERTENECEN Y SU NÚMERO DE INVENTARIO (A PARTIR DEL MAPA TOPOGRÁFICO NACIONAL DE ESPAÑA, ESCALA: 1: 25.000, HOJA 106 DE LA CARTA MILITAR ESPAÑOLA). ABAJO, UNA IMAGEN EN ORTOFOTOMAPA DE LA MISMA ÁREA, DONDE SE APRECIA, A LA IZQUIERDA, EL RIO ÁGUEDA Y SU DESEMBOCADURA EN EL DUERO (FUENTE: APPLE - MAPS) 
El Núcleo I tiene 3 rocas de cronología paleolítica, formando el conjunto principal del sitio con rocas decoradas de este período. Una, la roca II, está situada en la orilla izquierda del Arroyo de las Almas y tiene un sucinto grupo de líneas singularmente patinado y de difícil observación e interpretación, y cuya cronología paleolítica no podemos aseverar completamente. Las siguientes rocas paleolíticas son la 6 y la 7. La primera con un ciervo Magdaleniense, y la segunda con un posible caprino ejecutado en los momentos finales del Paleolítico superior (Figuras 8, I4 y I5). Estas dos rocas se encuentran muy cerca del final de un afluente del Arroyo de las Almas, a unos $20 \mathrm{~m}$ de distancia una de la otra, en la base del imponente afloramiento que ocupa gran parte de la orilla derecha del citado riachuelo; en uno de los puntos más reseñables en el paisaje del entorno del sitio del Arroyo de las Almas, con un destacado impacto visual (Figura 4).

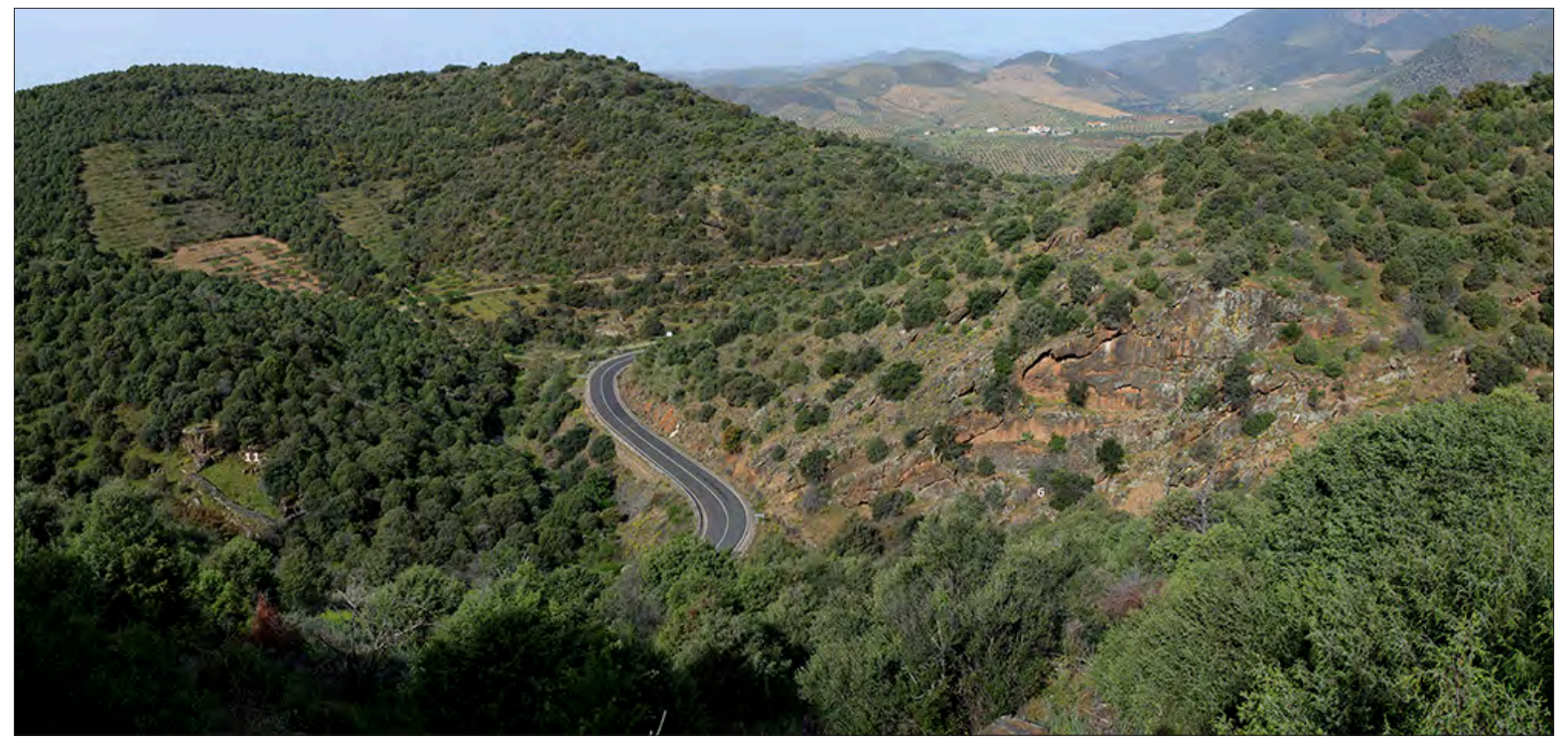

FIGURA 4. LOCALIZACIÓN DE LAS ROCAS 6, 7 Y 11 DEL NÚCLEO I

El Núcleo III corresponde a otro pequeño afluente, en la orilla derecha del Arroyo de las Almas, cuya desembocadura se localiza a unos $500 \mathrm{~m}$ aguas arriba de la del afluente del Núcleo I, teniendo un tamaño similar. Tan solo una de las 5 rocas catalogadas presenta figuras del Paleolítico superior, la roca 3, situada en la margen derecha del afluente, a I30 m de su desembocadura. Aquí, hemos inventariado un posible ciervo, acéfalo, de cronología Magdaleniense, en posición vertical, acompañado de varios signos y líneas sueltas (Figuras in y i4).

El Núcleo IV corresponde a un nuevo afluente del Arroyo de las Almas, con una similar longitud a los otros dos previamente referidos, aunque en esta ocasión su desembocadura se sitúa a unos $850 \mathrm{~m}$ de distancia, aguas abajo, del afluente del Núcleo I, y a unos I80o m del río Águeda. Este núcleo tiene una única roca grabada, un imponente abrigo aislado y situado en su margen derecha, a I8o m de la desembocadura, y con el mayor número de representaciones paleolíticas del conjunto. Los paneles 2, 6 y 7 son los que presentan figuras paleolíticas, con representaciones de caprinos, cérvidos y équidos, acompañados por uno u otro signo 
y abundantes líneas, que no siempre son fáciles de distinguir, atribuibles tanto al Magdaleniense inicial como al más reciente (Figuras I3, I5 y I6).

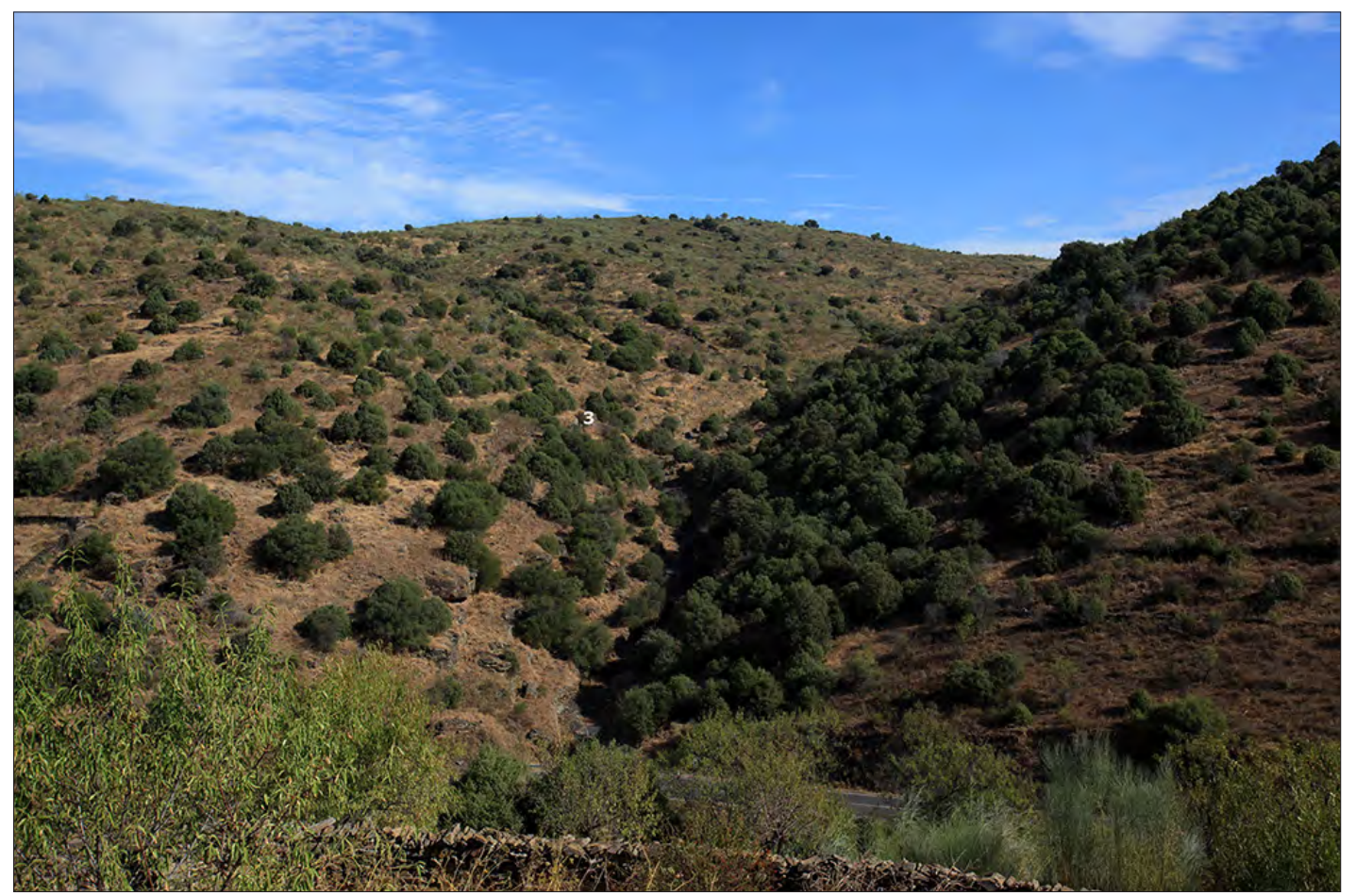

FIGURA 5. LOCALIZACIÓN DE LA ROCA 3 DEL NÚCLEO III

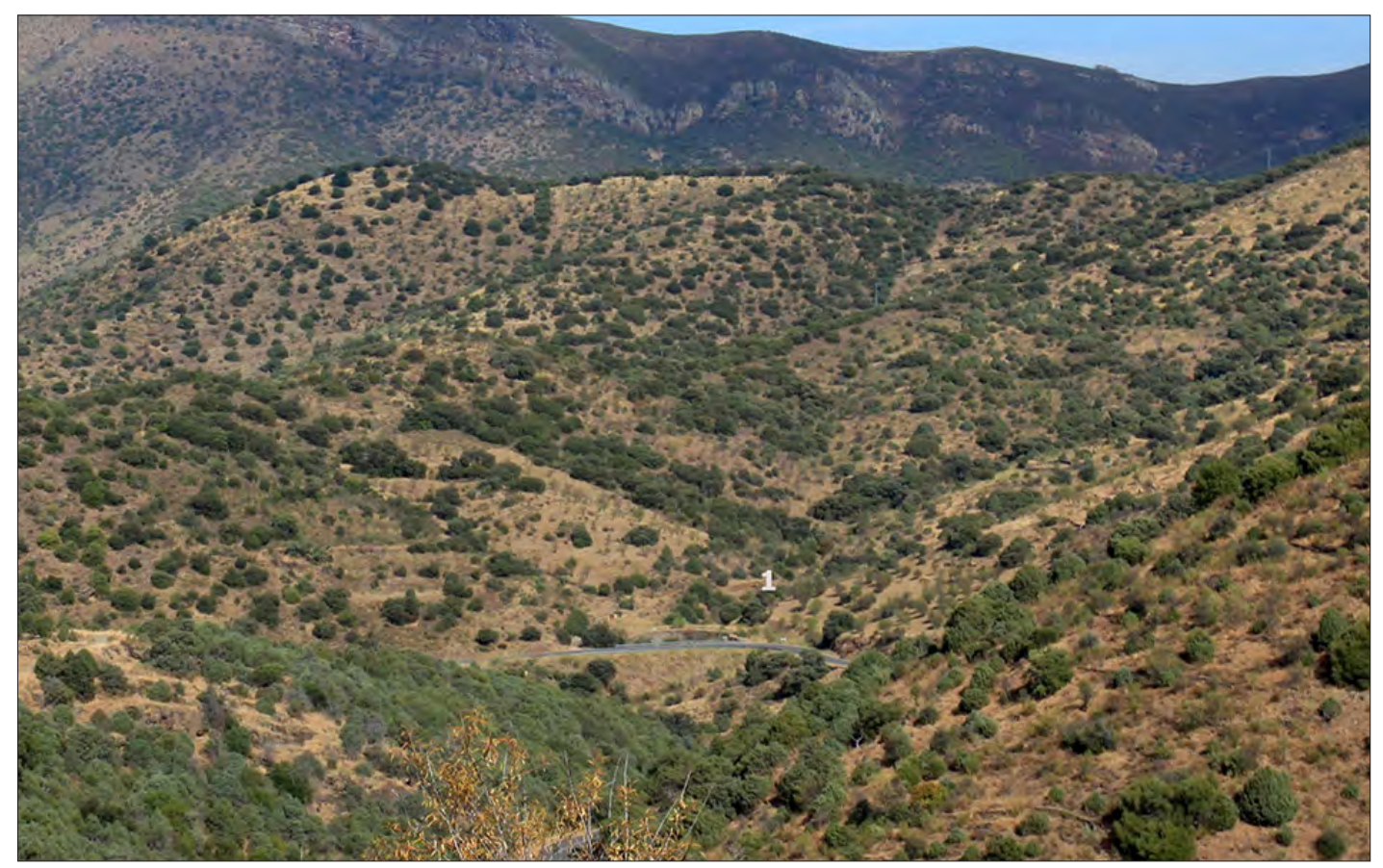

FIGURA 6. LOCALIZACIÓN DE LA ROCA I DEL NÚCLEO IV 


\section{DESCRIPCIÓN DE LOS MOTIVOS PALEOLÍTICOS INVENTARIADOS}

En la siguiente tabla presentamos las figuras paleolíticas inventariadas en el sitio rupestre del Arroyo de las Almas, ya sean motivos zoomorfos, signos o motivos indeterminables, describiendo, más abajo, por núcleos, cada una de ellas (Tabla I). Consideramos que todas estas figuras se insertan en el mismo período cronocultural, el Magdaleniense, distinguiendo, tras los análisis tipológicos y estilísticos elaborados, dos fases cronológicas diferentes. La Fase I correspondería al Magdaleniense inicial y reciente, con una cronología genérica, grosso modo, entre I8000 y I3000/12000 BP, y la Fase II, desde los momentos finales del Tardiglaciar hasta el Holoceno temprano, con una cronología entre los I3000/12000 y 9000 BP.

\begin{tabular}{|c|c|c|c|c|c|c|c|}
\hline MOTIVO & NÚCLEO & ROCA & PANEL & TEMA & DIMENSIÓN (CM) & FASE & FIGURA \\
\hline 1 & I & 6 & 1 & Cérvido & 24 & I & 8,14 y 16 \\
\hline 2 & I & 7 & 1 & Caprino & 12 & II & 8 y 16 \\
\hline 3 & I & 11 & 1 & Indeterminable & 11 & II & - \\
\hline 4 & III & 3 & 2 & Cérvido & 24 & I & 11,14 y 16 \\
\hline 5 & III & 3 & 2 & Signo & 18 & I & 14 \\
\hline 6 & III & 3 & 2 & Signo: oval & 3 & I & 14 \\
\hline 7 & III & 3 & 2 & Signo: línea segmentada & 8 & I & 14 \\
\hline 8 & IV & 1 & 2 & Signo: oval & 2 & $\mathrm{I} / \mathrm{II}$ & 12 \\
\hline 9 & IV & 1 & 2 & Signo: fusiforme & 7 & $1 / I I$ & 12 \\
\hline 10 & IV & 1 & 6 & Caprino & 7 & II & 13,15 y 16 \\
\hline 11 & IV & 1 & 6 & ¿Cérvido? & 5 & II & 15 y 16 \\
\hline 12 & IV & 1 & 6 & Signo & 8 & II & 15 \\
\hline 13 & IV & 1 & 6 & Cérvido & 6 & I & 13,15 y 16 \\
\hline 14 & IV & 1 & 6 & Cérvido & 2,5 & I & 15 y 16 \\
\hline 15 & IV & 1 & 7 & Cérvido & 4 & I & 13,15 y 16 \\
\hline 16 & IV & 1 & 7 & Équido & 20 & I & 15 y 16 \\
\hline 17 & IV & 1 & 7 & Équido & 21 & I & 15 y 16 \\
\hline 18 & IV & 1 & 7 & Signo: trazos paralelos & 2 & I & 15 \\
\hline 19 & IV & 1 & 7 & Équido & 10 & 1 & 13,15 y 16 \\
\hline 20 & IV & 1 & 7 & Équido & 14 & I & 15 y 16 \\
\hline 21 & IV & 1 & 7 & Cuadrúpedo Indeterminable & 25 & I & 15 y 16 \\
\hline
\end{tabular}

TABLA 1. RELACIÓN DE LOS MOTIVOS PALEOLÍTICOS INVENTARIADOS 


\subsection{NÚCLEO I}

Del primer núcleo del Arroyo de las Almas, el más densamente grabado y con el mayor número de rocas y motivos, destacaremos, de las 3 rocas paleolíticas inventariadas, la roca 6 . Esta, no solo tiene alguno de los motivos más antiguos del yacimiento del Arroyo de las Almas, sino que muestra, además, varias de las peculiaridades técnicas y formales más relevantes de las percibidas en las figuras paleolíticas del yacimiento.

Situada en la base de un amplio macizo rocoso, a pocos metros de la margen derecha del arroyo y orientada hacia él, esta primera roca paleolítica se encuentra muy cerca de la carretera CL-5I7 (Figura 4). Aquí, y sobre una superficie vertical de, al menos, 4,5 $\mathrm{m}$ de long. y más de $2 \mathrm{~m}$ de alt., se concentran todos sus grabados, donde la superficie pizarrosa y esquistosa se encuentra mejor conservada, en la extremidad derecha. Aquende, distinguimos dos paneles diferentes con grabados paleolíticos. El primero es el más relevante: un ciervo grabado de cronología paleolítica que fue descubierto en septiembre de 2015, asociado a un trazo lineal y a un motivo de cronología mas reciente (Reis \& Vázquez Marcos 2015: 4I). El segundo panel, a la izquierda, presenta un conjunto de trazos de cronología paleolítica y de difícil comprensión.

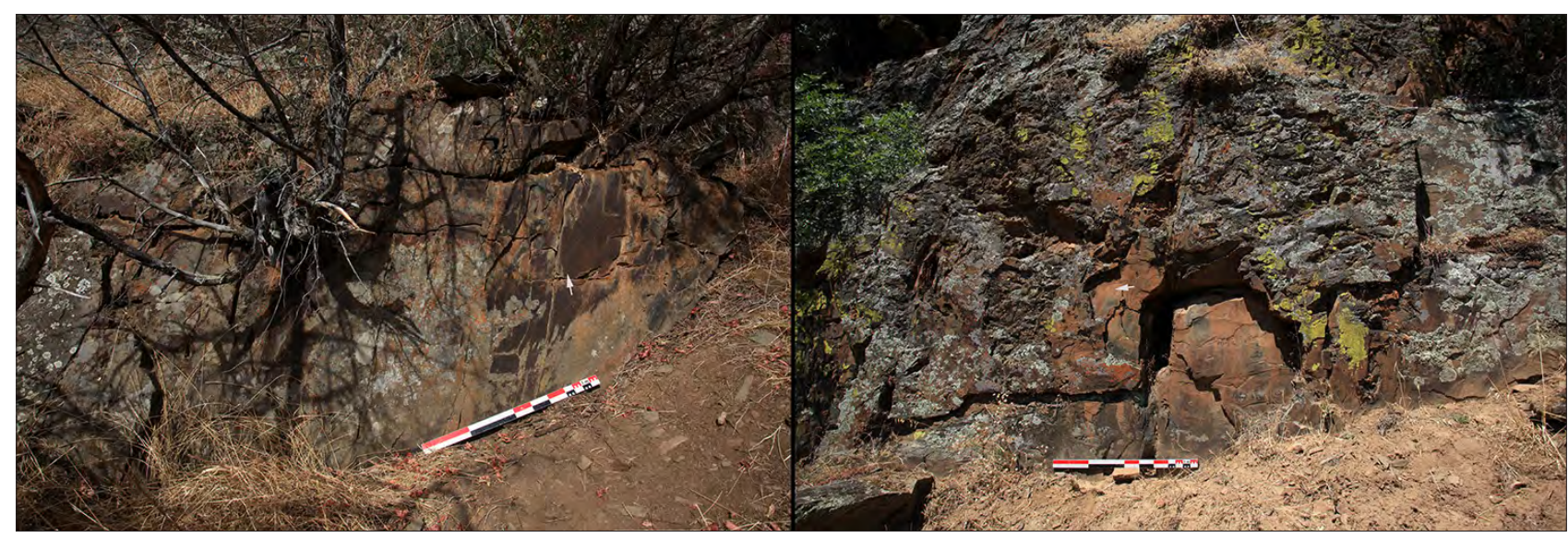

FIGURA 7. A LA IZQUIERDA, ROCA 6 DEL NÚCLEO I. LA FLECHA INDICA LA LOCALIZACIÓN DEL CIERVO GRABADO. A LA DERECHA, ROCA 7 DEL NÚCLEO I. LA FLECHA INDICA LA LOCALIZACIÓN DEL CAPRINO GRABADO

Motivo I. Ciervo grabado en trazos únicos y repetidos, combinando, por tanto, varias modalidades de incisión. Se localizó en la parte alta del panel I, en su lado izquierdo, conservándose completo, a $74 \mathrm{~cm}$ del suelo actual. Destacar, además de su cornamenta, una rama trasera separada en varios candiles, bifurcados, y las tres puntas delanteras. La cabeza es triangular, con el morro, $\mathrm{u}$ hocico, redondeado, teniendo grabada la línea fronto-nasal, una larga oreja, la boca, realizada mediante una fina incisión horizontal, y un despiece en el cuello-pecho indicando la diferente longitud del pelaje y coloración que tiene en ese punto el animal. Asimismo, se puede observar una fina línea grabada que señala el despiece escapular. También se percibe su línea cérvico-dorsal recta, que termina en una peculiar y levantada grupa y en una cola corta. No fue grabado el vientre aunque pudo ser aprovechado el oscuro 
soporte con este fin. Con perspicuidad también se perciben tanto las extremidades anteriores como las posteriores, una por par, representadas estas últimas «en Y» (Figuras 8 y I4).

En esta roca hay más trazos grabados, aparentemente no figurativos. Uno es un pequeño trazo lineal inciso situado en las inmediaciones del cuarto trasero del ciervo.

En el panel 2, a menos de I $\mathrm{m}$ a la izquierda del ciervo, aparece un conjunto de trazos lineales ejecutados mediante un fino y único trazo inciso. Surgen en diferentes disposiciones (vertical, horizontal y oblicua), con desiguales dimensiones y sin conexión evidente entre ellos. La semejanza, en la pátina y en el tipo de trazo observado con las representaciones documentadas en este mismo panel, nos proporciona argumentos suficientes para incluirlo en la misma fase cronológica propuesta para el ciervo.

La roca 7 se encuentra en las inmediaciones de la anterior roca, a $25 \mathrm{~m}$ aprox., en la margen derecha y en la base del macizo rocoso. A pesar de su proximidad, lo encajado del valle impide la visibilidad directa entre ambas. Se trata de un pequeño panel vertical con una figura zoomorfa y dos conjuntos de trazos, orientado a la línea de agua e inserto en el gran conjunto rocoso del desfiladero.

Motivo 2. Caprino ejecutado por grabado inciso (Figura 8). Se puede observar que las extremidades anteriores fueron grabadas con un único trazo, contrariamente a lo realizado en las extremidades posteriores, con pezuña y corvejón, con múltiples trazos rellenándolas. La cabeza tiene una anómala forma sin detalle anatómico interno, más allá de dos largos cuernos, curvos y hacia atrás. Los abundantes rellenados internos de su cuerpo y cuarto trasero, y larga cola que finaliza en una peculiar forma tridentada junto a la rectitud de su línea cérvico-dorsal, nos impiden aseverar, de forma irrebatible, la asignación zoomorfa citada ya que bien podría tratarse de otro animal por algunos de estos rasgos anatómicos descritos. Esta figura, que pierde el naturalismo de otras figuras de animales del sitio, está asociada a dos conjuntos de trazos. El primero es un conjunto de trazos lineales grabados mediante incisión y dispuestos en posición vertical, horizontal y oblicua, en una pequeña zona del panel y por encima del caprino. Algunas de estas delineaciones se encuentran infrapuestas al caprino, mostrando una pátina más antigua. El segundo es un conjunto de trazos lineales grabados por incisión y situados por debajo del animal, presentando una forma rectangular.

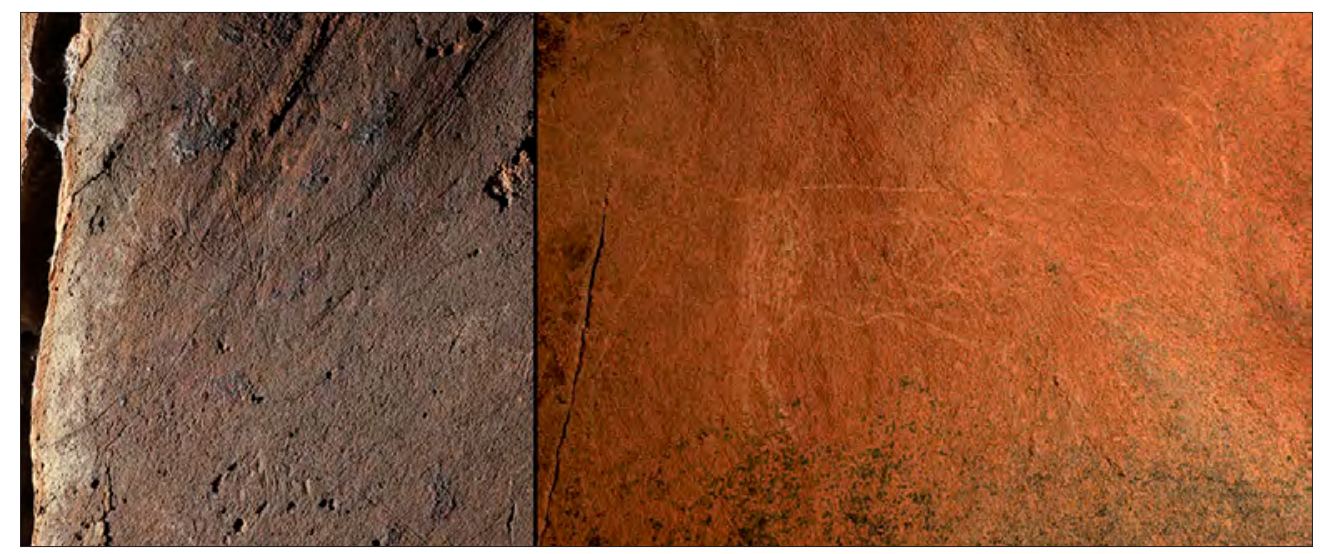

FIGURA 8. A LA IZQUIERDA, CABEZA DEL CIERVO DE LA ROCA 6 DEL NÚCLEO I (MOTIVO I) CON SUS EXUBERANTES ASTAS. A LA DERECHA, POSIBLE CAPRINO DE LA ROCA 7 DEL NÚCLEO I (MOTIVO 2) 
La roca in se asienta en la margen izquierda del Arroyo de las Almas, en un extenso macizo rocoso donde también fueron localizadas las rocas I, 2, 3 y io de este mismo núcleo. Se encuentra a poco más de $50 \mathrm{~m}$ de la desembocadura del pequeño afluente con el Arroyo de las Almas, y a unos $140 \mathrm{~m}$ de distancia en línea recta de la primera de las rocas descritas, la roca 6 . Se trata de una gran superficie vertical e irregular, orientada hacia el arroyo, que mide aprox. 2,5 $\mathrm{m}$ de alt. por 5,5 $\mathrm{m}$ de anch. Tiene un pequeño panel, en el sector central derecho, a I,2 m del suelo actual, situado sobre una plataforma plana y ancha que permite el acceso. Aquí, observamos un motivo indeterminable que hemos decidido valorar y contabilizar en nuestro inventario, al haber sido grabado mediante una incisión realizada con instrumento lítico, como indica su sección, con una modalidad de grabado inciso raramente observada para llevar a cabo otros motivos de cronología postpaleolítica.

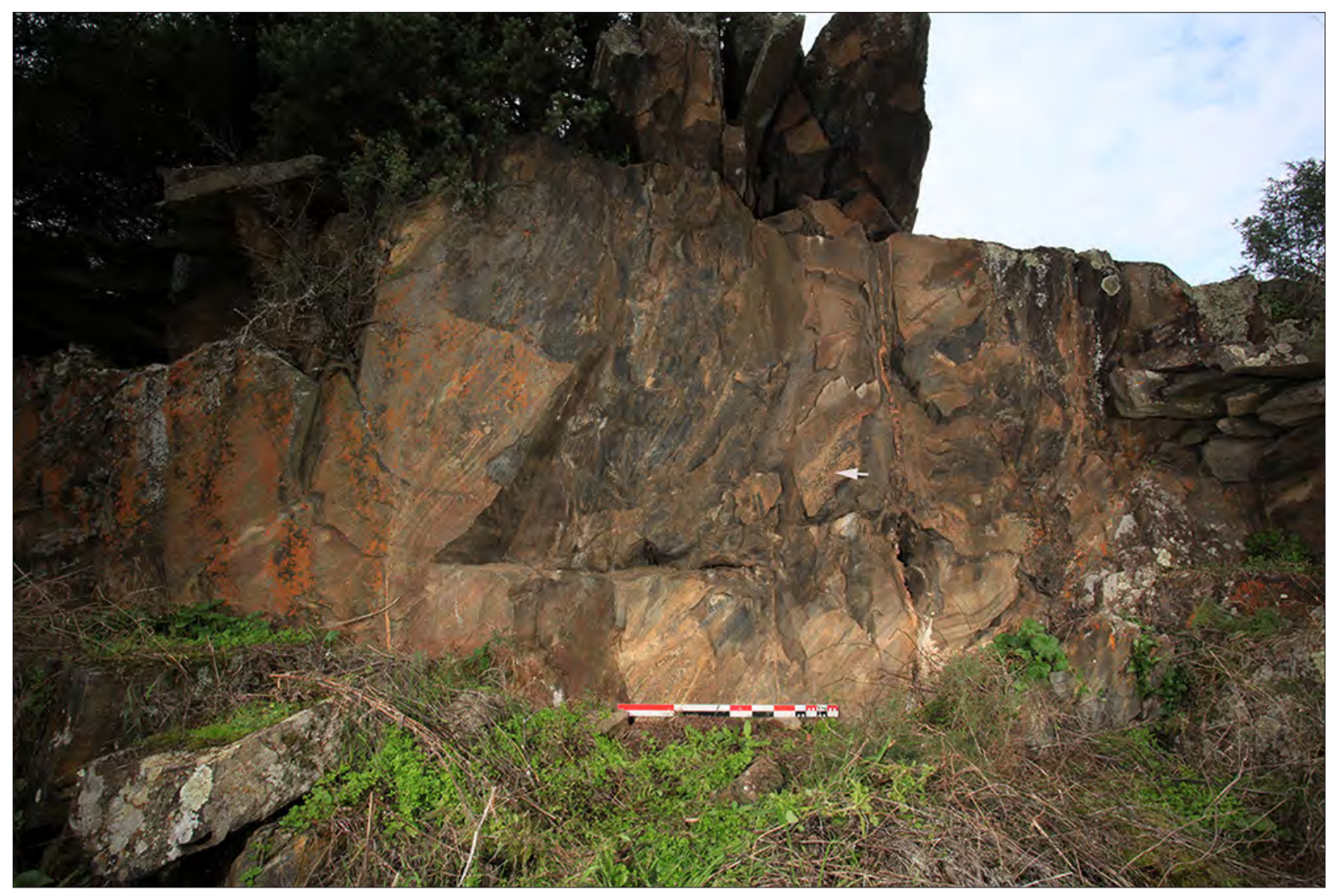

FIGURA 9. ROCA II DEL NÚCLEO I. LA FLECHA INDICA LA LOCALIZACIÓN DE LOS TRAZOS GRABADOS

Motivo 3. Figura indeterminable localizada en la roca in que podría corresponder tanto al vientre y las extremidades anteriores de un animal, que mira a la derecha del observador, como a un signo. A su alrededor hemos percibido la presencia de varios pequeños trazos grabados mediante incisión, cubiertos, en parte, por minúsculos fragmentos de materia orgánica que en estas pizarras y esquistos han fomentado los procesos de oxidación tanto de hierro como de manganeso. 


\subsection{NÚCLEO III}

En el Núcleo III solo una roca presenta motivos paleolíticos, la roca 3, situada en la margen derecha del regato, a unos $20 \mathrm{~m}$ sobre el lecho de la rivera y a I4O $\mathrm{m}$ de su desembocadura en el Arroyo de las Almas. Es una gran roca aislada y con una apta superficie vertical, orientada a la línea de agua, con aprox. 5,5 $\mathrm{m}$ de long. por 2,2 $\mathrm{m}$ de alt. En el panel 2 destaca una figura acéfala, tal vez un cérvido, asociado a tres diferentes signos, además de a varios otros conjuntos de trazos de muy difícil percepción, formando una de las mayores asociaciones de este tipo de representaciones en las 5 rocas paleolíticas de Arroyo de las Almas (Figura I4).

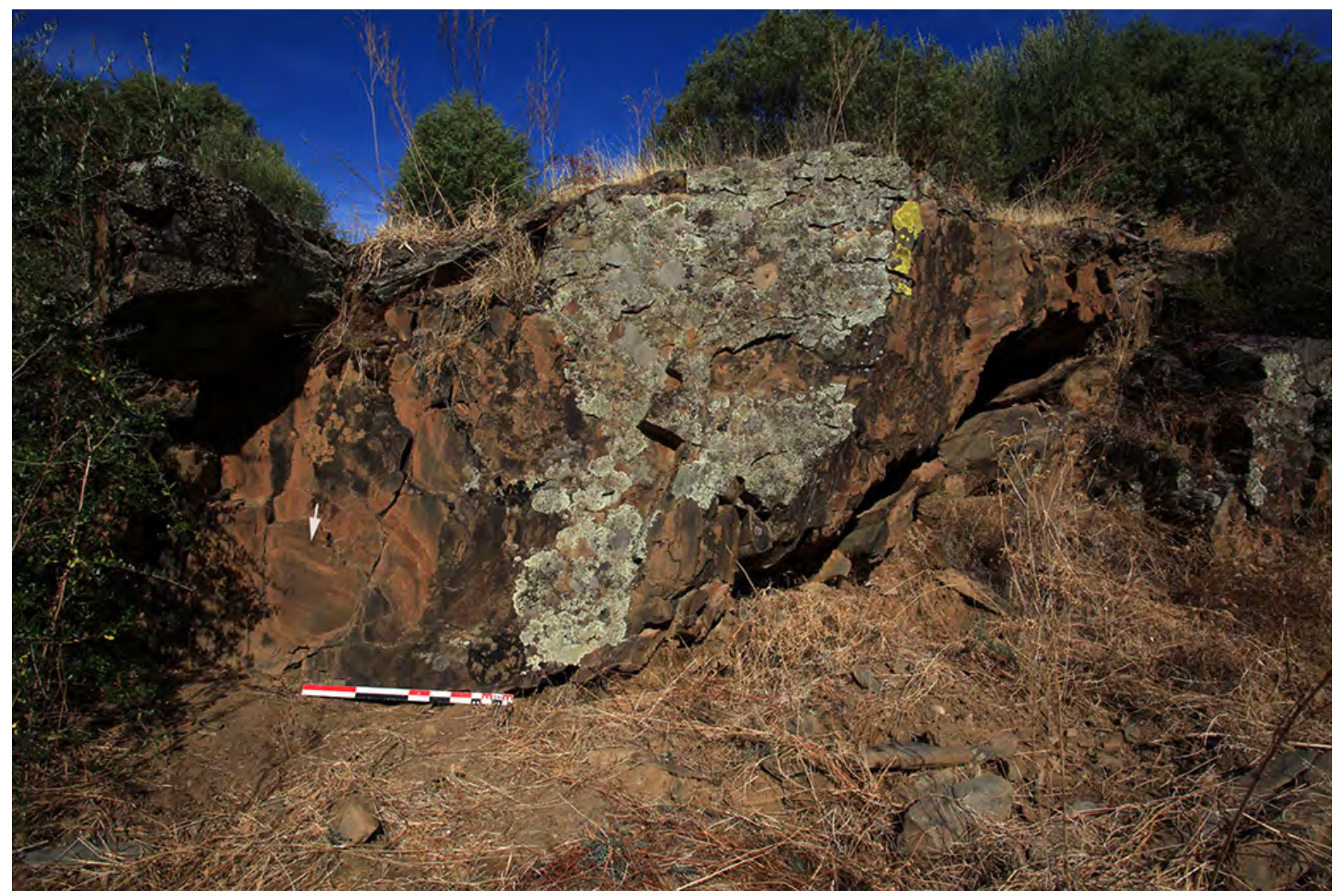

FIGURA 10. ROCA 3 DEL NÚCLEO III. LA FLECHA INDICA LA LOCALIZACIÓN DEL PANEL GRABADO

Motivo 4. Posible ciervo, grabado por incisión en trazos únicos y repetidos. Excepto por su cabeza, que aparentemente no fue grabada, el animal fue ejecutado en su totalidad. Queremos incidir, con respecto a su descripción, tanto en su pequeña cola como continuación de una lograda recta línea cérvico-dorsal como en su inacabada línea del cuello-pecho o en las dos extremidades posteriores, de muy bella factura, ejecutadas mediante dos líneas sin cerrar en su final y con el corvejón. Además, en este animal, grabaron tanto el despiece ventral, señalando el cambio cromático de su pelaje en este punto, como la zona inguinal y tres líneas incisas a la altura de la nuca que aparentemente indican la pelambrera junto a la oreja y un posible cuerno. Este último atributo anatómico, junto a otros, nos ha 
impedido definir con seguridad la especie descrita, pudiendo, además de cérvido, corresponder a un caprino. El zoomorfo, situado en posición oblicua y orientado hacia abajo, se encuentra superpuesto a una línea curva que aparentemente simula una pequeña loma o elevación además de estar asociado a otros tres signos.

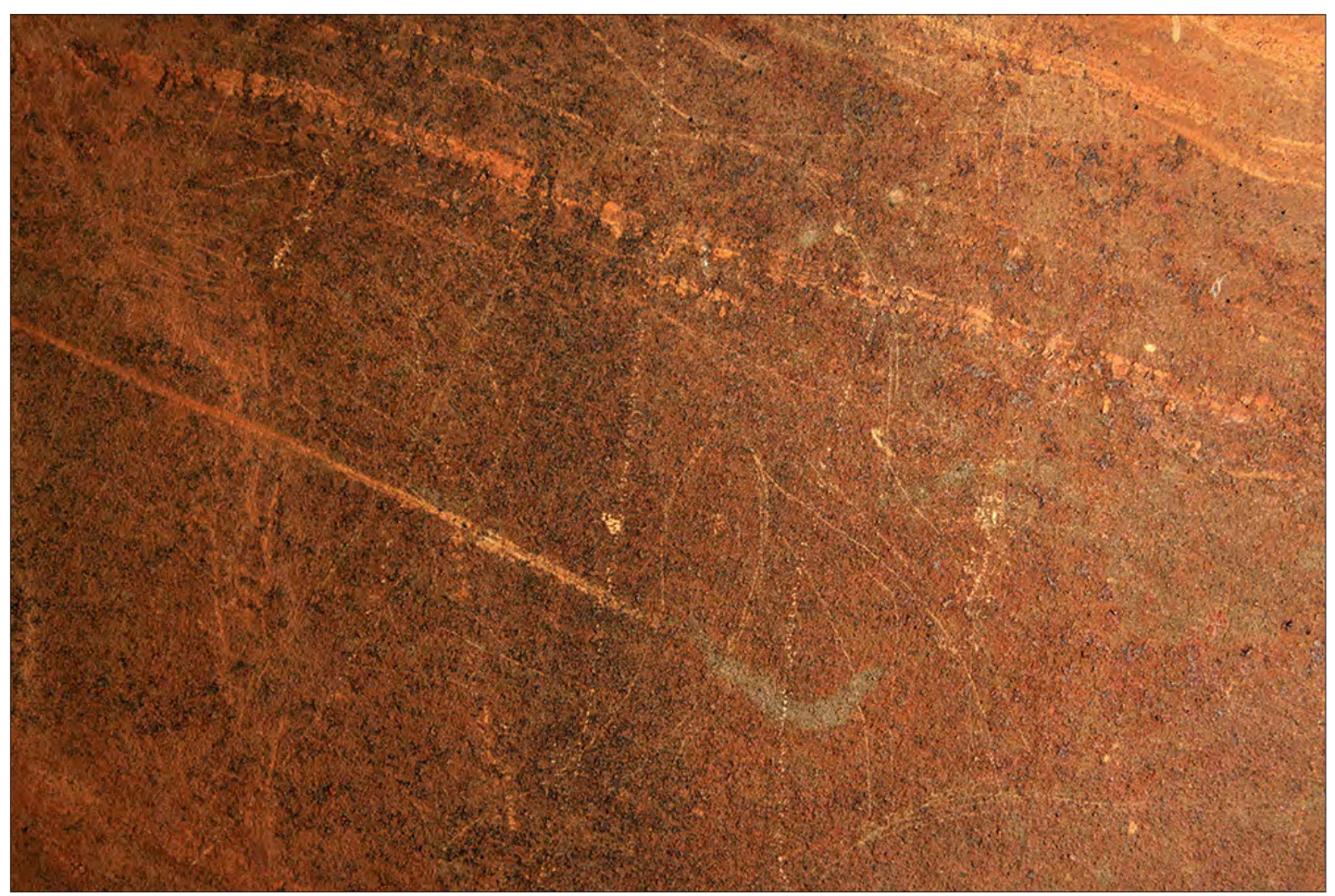

FIGURA 11. CUERPO DEL ANIMAL ACÉFALO DEL PANEL 2 DE LA ROCA 3 DEL NÚCLEO III (MOTIVO 4), SE OBSERVA EL DESPIECE VENTRAL Y EL SIGNO ASOCIADO A SU CUARTO TRASERO (MOTIVO 7)

Motivo 5. Signo constituido por un conjunto organizado de trazos oblicuos, verticales y horizontales, en la parte superior del panel, de al menos 25 líneas grabadas mediante incisión en trazo único.

Motivo 6. Signo con forma oval, sin cerrar, situado por encima de la línea cérvicodorsal del Motivo 4, a menos de $8 \mathrm{~cm}$. Tiene, en su interior, al menos siete finas líneas finamente grabadas, siendo similar al Motivo 8, del Núcleo IV.

Motivo 7. Signo constituido por un trazo horizontal que se inicia junto a la extremidad trasera del Motivo 4, superpuesto por 5 trazos pequeños verticales paralelos y de diversas longitudes (Figuras II y I4).

En este pequeño panel existen, además, diversos conjuntos individualizables de líneas grabadas pero que no tienen formas reconocibles, pareciendo inconexas y no figurativas. Así, entre los Motivos 4 y 5 se encuentra un conjunto de líneas grabadas por incisión, únicas y repetidas, cinco verticales, una horizontal y otra oblicua. Además, y ubicadas en la parte superior de la Motivo 4, sobre su línea cérvico-dorsal, surge un conjunto de líneas grabadas por incisión, únicas y repetidas. Figuradamente podrían estar constituyendo parte de un motivo zoomorfo o signo. Por otro lado, rodeando el Motivo 6 y el conjunto de líneas anteriormente descrito, y penetrando en el Motivo 4, hay un caótico conjunto de pequeñas líneas grabadas por incisión, 
verticales, horizontales y oblicuas. Enseguida, I8 $\mathrm{cm}$ a la derecha del Motivo 4, surge un conjunto de líneas grabadas por incisión, en trazo único y con forma curvilínea. Para terminar, un conjunto de largas líneas grabadas por incisión, en trazo único y curvadas, que se inicia por debajo del motivo zoomorfo y se prolonga hacia la derecha.

\subsection{NÚCLEO IV}

El último de los núcleos desvelados, el Núcleo IV, se encuentra en un pequeño regato, afluente del Arroyo de las Almas por su derecha, entre el teso Cabeza de Cántaro y el de Colmenar, a poco más de i km en línea recta del río Águeda y muy cerca del despoblado de San Martín. En él, localizamos un enorme y único abrigo rocoso de pizarra poco profundo.

El abrigo, que mide 3,5 $\mathrm{m}$ de alt. y, al menos, Io $\mathrm{m}$ de anch., se sitúa en la margen derecha del afluente y por encima de este, a I80 $\mathrm{m}$ de su desembocadura, teniendo una accesible plataforma que permite el acceso hasta los paneles grabados. La pared del fondo, orientada al regato, tiene una peculiar forma irregular que se divide en múltiples paneles, de los cuales solo una pequeña parte fue decorada. Los motivos paleolíticos se encuentran en los paneles 2,6 y 7 , con varias representaciones zoomorfas inventariadas, sobre todo caprinos, cérvidos y équidos, acompañadas de diversos signos y grupos de trazos sueltos, no siempre fáciles de distinguir (Figuras I3, I5 y I6). Es posible que haya más motivos y conjuntos de trazos en estos paneles no considerados en la descripción, por la dificultad en su detección.

El panel 2 aparece en la zona central izquierda del abrigo, a gran altura, a $2 \mathrm{~m}$ aprox. del suelo actual, y con un acceso a los motivos que se ve facilitado por varias plataformas rocosas que permiten el apoyo. Los paneles 6 y 7 se encuentran en la parte derecha del abrigo, el primero a poco más de I $\mathrm{m}$ del suelo, y el último a más de $2 \mathrm{~m}$.

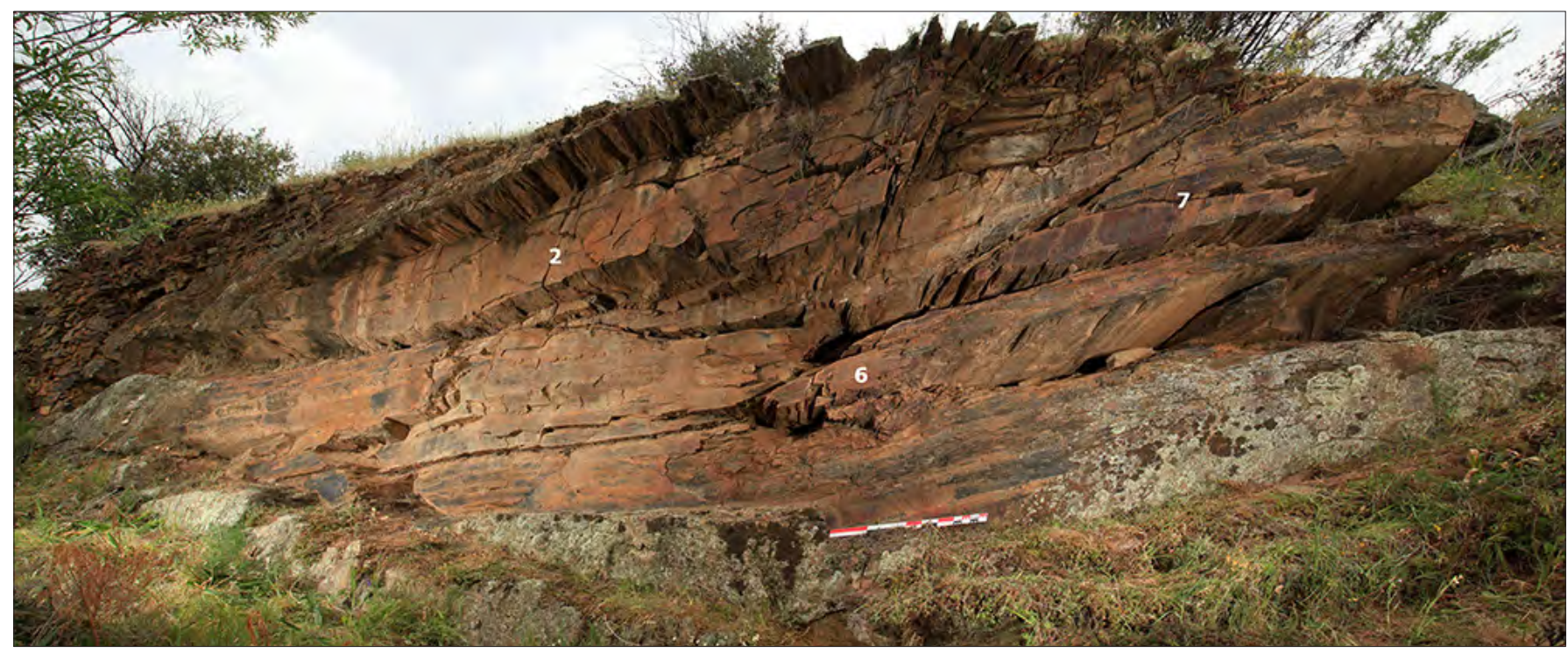

FIGURA 12. SUPERFICIE DECORADA DE LA ROCA I DEL NÚCLEO IV, SE INDICA LA LOCALIZACIÓN DE LOS PANELES 2, 6 Y 7, CON GRABADOS DEL PALEOLÍTICO SUPERIOR 
Nos resta destacar, dentro del arte Paleolítico catalogado del Núcleo IV, el sector inferior del panel 7, que presenta un magnífico friso de prótomos de équidos, a los que se une otro peculiar animal de difícil identificación. Entre estos équidos se encuentran algunas de las más antiguas representaciones del sitio, remontándose al Solutrense final o Magdaleniense inicial, además de tener, desde el punto de vista estético, algunas de las figuras más logradas y contribuir con esto, decididamente, a hacer del Arroyo de las Almas un importante sitio con arte Paleolítico, no solo al aire libre.

Motivo 8. Signo oval de muy pequeñas dimensiones. Se sitúa a media altura y en el sector izquierdo del panel $2,75 \mathrm{~cm}$ a la izquierda del Motivo 9. Llevado a cabo por grabado inciso, en trazos únicos y finos, consiste en un ovalo cerrado, en posición oblicua, y con múltiples rasgos paralelos en su interior.

Motivo 9. Signo fusiforme. Se localizó en el sector intermedio y central del panel $2,75 \mathrm{~cm}$ a la derecha del Motivo 8 .

Motivo 1o. En el panel 6 documentamos una cabra incompleta, en la parte inferior izquierda del panel, en la que se identifican tanto sus dos cuernos, con abundantes rellenados internos ejecutados con trazos lineales incisos y verticales, la línea fronto-nasal, el morro redondeado y una extremidad anterior como continuación del cuello-pecho. Tras su cabeza, da comienzo la línea cérvicodorsal, ejecutada con varios trazos repetidos, sin que podamos observar, de forma clara, la línea del vientre u otros rasgos anatómicos del animal. Destacar, además, su intencional estilo subnaturalista y la modalidad técnica de grabado utilizada, propias de los momentos finales del Tardiglaciar y de su transición al Holoceno Temprano.

Motivo II. Posible cierva situada por debajo del Motivo io, a la izquierda. Está completa y pese a sus pequeñas dimensiones y la dificultad que entraña su observación, es posible apreciar su peculiar e irregular cabeza ovalada, con una oreja, la línea del cuello-pecho y la cérvico-dorsal, y una corta y redondeada cola además de la línea ventral. Está ejecutada en trazos simples además de repasados en el vientre y en el pecho, pudiendo ser atribuida a otra especie zoomorfa con base en varios paralelos morfotipológicos conocidos.

Motivo I2. Conjunto de líneas incisas aparentemente conectadas, con orientaciones divergentes, que conforman un motivo abstracto de difícil clasificación, junto al Motivo in y en la parte inferior del fracturado panel 6. Son muchas las dudas que genera dicho conjunto, no pudiendo rechazar una propuesta tipológica diferente.

Motivo I3. Cierva grabada mediante incisión, casi completa, localizada en la extremidad derecha inferior del panel $6,40 \mathrm{~cm}$ a la derecha del Motivo Io. Sobresale, por encima de otros rasgos y atributos anatómicos, su morro apuntado y las dos orejas, cortas, afiladas y en perspectiva correcta, con abundantes trazos en su interior además de una perceptible línea cérvico-dorsal, el vientre abombado, la grupa, la cola, que se ve interrumpida por una grieta, y dos cortas extremidades posteriores. No se perciben las extremidades anteriores que, aparentemente, no fueron representadas. La figura descrita, como otras catalogadas en este panel, se encuentra a I $m$ del peldaño pétreo. 
Motivo I4. Prótomo de cierva, situado a poco más de $10 \mathrm{~cm}$ a la derecha del Motivo I3. Ejecutada mediante un fino grabado inciso, con una forma muy esquematizada, esta unidad fue confeccionada gracias a dos líneas casi paralelas, simulando el pecho y el dorso, y rematadas por dos líneas unidas en el vértice que conformaron la acentuada cabeza triangular que exhibe, ligeramente redondeada en la quijada. A pesar del esquematismo observado, tienes rasgos, convenciones gráficas y atributos cronológicos similares a los descritos para el Motivo I3.

En el panel 6 se han observado, al menos, tres conjuntos distintos y no figurativos de trazos. El primero es un pequeño conjunto de trazos incisos agrupados en horizontal, y localizados a la izquierda del Motivo io y por encima de los Motivos II y I2, además de asociados a algunos trazos grabados por abrasión profunda, aunque infrapuestos a los primeros. También es posible observar varios trazos superpuestos, con una pátina diferente que los paleolíticos, y de ejecución más reciente. El segundo es un grupo de trazos largos y paralelos, tendentes a la horizontalidad, a la izquierda del Motivo I3. Están superpuestos por filas de trazos incisos verticales posteriores, presentando, alguno de ellos, una longitud, profundidad y aspecto visual muy similar al de los trazos que conforman el Motivo i3. A la derecha del Motivo I3 y debajo del Motivo I4 aparece un largo trazo curvilíneo inciso, en horizontal, y asociado a otros dos trazos más cortos a la derecha, con los que converge.

Motivo 15. En el panel 7 reconocimos un prótomo de cierva en la extremidad superior derecha del panel, a más de $2 \mathrm{~m}$ de altura del suelo actual del abrigo. Ejecutada por trazos finos y únicos, qué en ocasiones, fueron repetidos, son pocos los detalles anatómicos que tiene. Orientada a la derecha del observador y ligeramente inclinada hacia arriba, la figura conserva un morro entre apuntado y redondeado, la recta línea cérvico-dorsal, el cuello-pecho y el arranque de las extremidades anteriores. Destacar, de su cabeza, además de su ovalada forma, las abundantes líneas grabadas por trazos repetidos y únicos que se pueden observar en su interior.

En esta misma área del panel 7, e infrapuestos al Motivo I5, se pueden contemplar numerosos trazos grabados por incisión, preferentemente en trazo único. Estos ocupan una considerable parte del panel, $34 \mathrm{~cm}$ de larg. por $\mathrm{I} 9 \mathrm{~cm}$ de anch. aprox., no habiendo sido posible identificar motivo figurativo alguno, por el deficiente estado de conservación que complejiza enormemente su lectura.

Motivo I6. Prótomo de équido grabado mediante incisiones en trazo único y repetido, orientado hacia la derecha del observador. Se encuentra en la parte izquierda del panel 7, aprovechando su parte más idónea. Pese a las dificultades de observación, por la peculiar coloración del panel y su defectuoso estado de conservación, se perciben tanto la línea fronto-nasal como la que corresponde a la quijada, ambas rectas y ejecutadas con múltiples trazos incisos continuos y discontinuos, y el morro apuntado y sin cerrar. El animal carece, además, de reseñables detalles anatómicos internos aunque su pecho-cuello fue iniciado con la misma modalidad técnica que los citados atributos al igual que la línea cérvicodorsal y la doble crinera enhiesta con, al menos, cuarenta trazos que en algunos 
casos podrían corresponder tanto a las orejas, inclinadas hacia adelante, como al tupé del équido. Se separa por una grieta vertical del Motivo I7.

Motivo I7. Prótomo de équido grabado mediante incisiones en trazos únicos y repetidos, y orientado hacia la derecha del observador. Está situado a la derecha del Motivo I6, a menos de Io $\mathrm{cm}$. Pese a las dificultades de observación, se perciben, como en la figura anteriormente descrita, tanto la línea naso-frontal como la quijada aunque en este caso han sido ejecutadas, ambas, por líneas en trazo único. El morro del animal también es diferente al del Motivo i6 al estar cerrado y tener una redondeada morfología. Carece, además, de detalles anatómicos internos aunque su pecho-cuello fue iniciado por, al menos, tres trazos, siendo el principal más profundo que los otros dos. Su crinera enhiesta tiene el mismo número de trazos que la figura anterior aunque aquellos que se infraponen a los verticales y simulan la doble crinera, en el Motivo I7, son más numerosos que en el Motivo i6. Como en este último, varios de estos trazos podrían corresponder tanto a las orejas, inclinadas hacia adelante, como al tupé del équido.

Motivo I8. Conjunto de pequeños trazos lineales paralelos, grabados por incisión, y situados junto al redondeado morro del équido inventariado como Motivo I7, a menos de i cm.

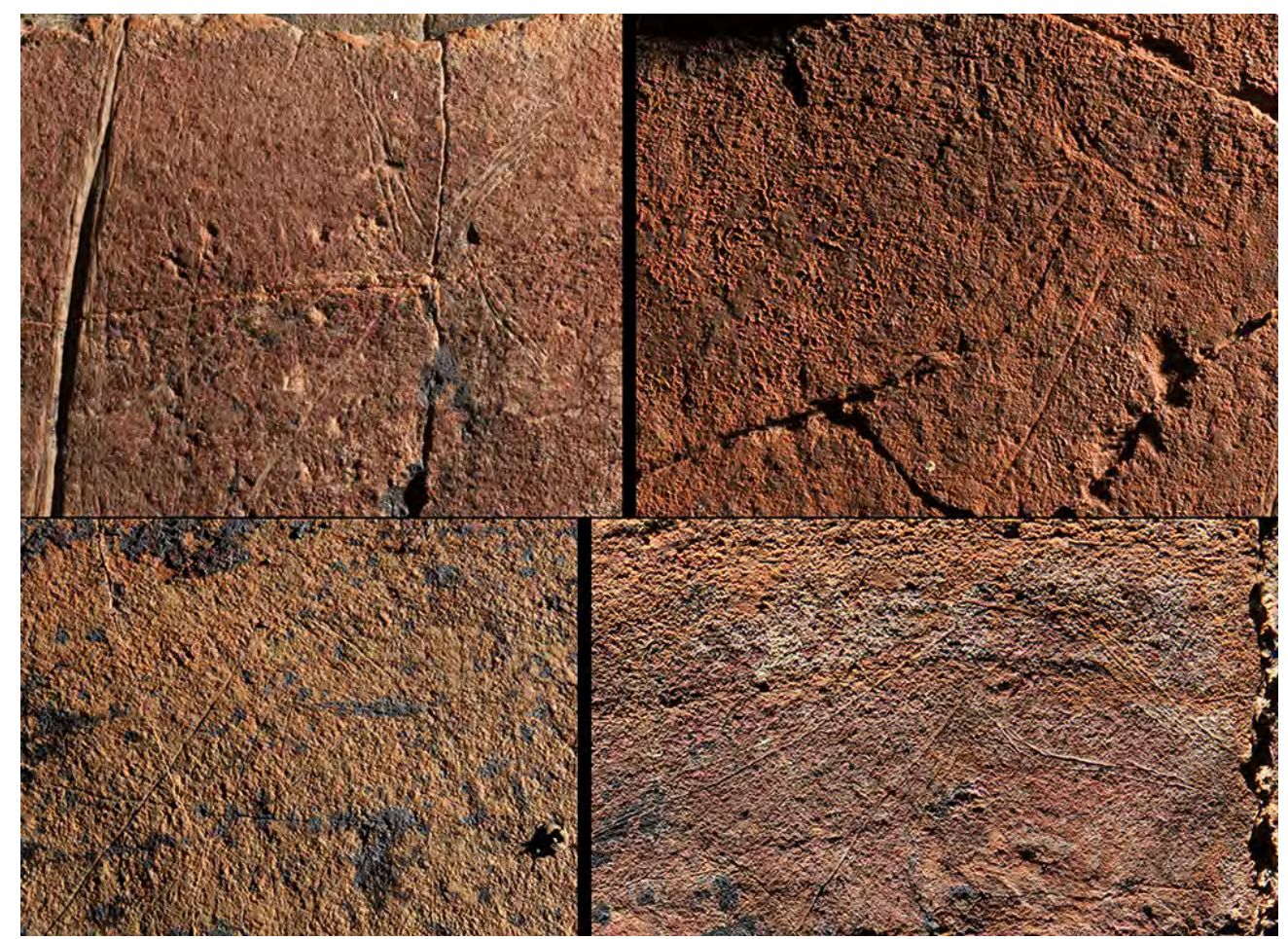

FIGURA 13. DETALLES DE ALGUNOS DE LOS MOTIVOS PALEOLÍTICOS DE LA ROCA I DEL NÚCLEO IV. ARRIBA, CAPRINO A LA IZQUIERDA (MOTIVO 10) Y CIERVA A LA DERECHA (MOTIVO 13). ABAJO, CIERVA A LA IZQUIERDA (MOTIVO 15) Y ÉQUIDO A LA DERECHA (MOTIVO 19)

Motivo I9. Prótomo de équido grabado mediante incisiones en trazos únicos y repetidos. Está orientado hacia la derecha del observador, por encima del Motivo I7, a menos de $5 \mathrm{~cm}$. Pese a las dificultades de observación, se perciben, como en figuras descritas, tanto la línea fronto-nasal como la quijada convexa ejecutadas ambas por 


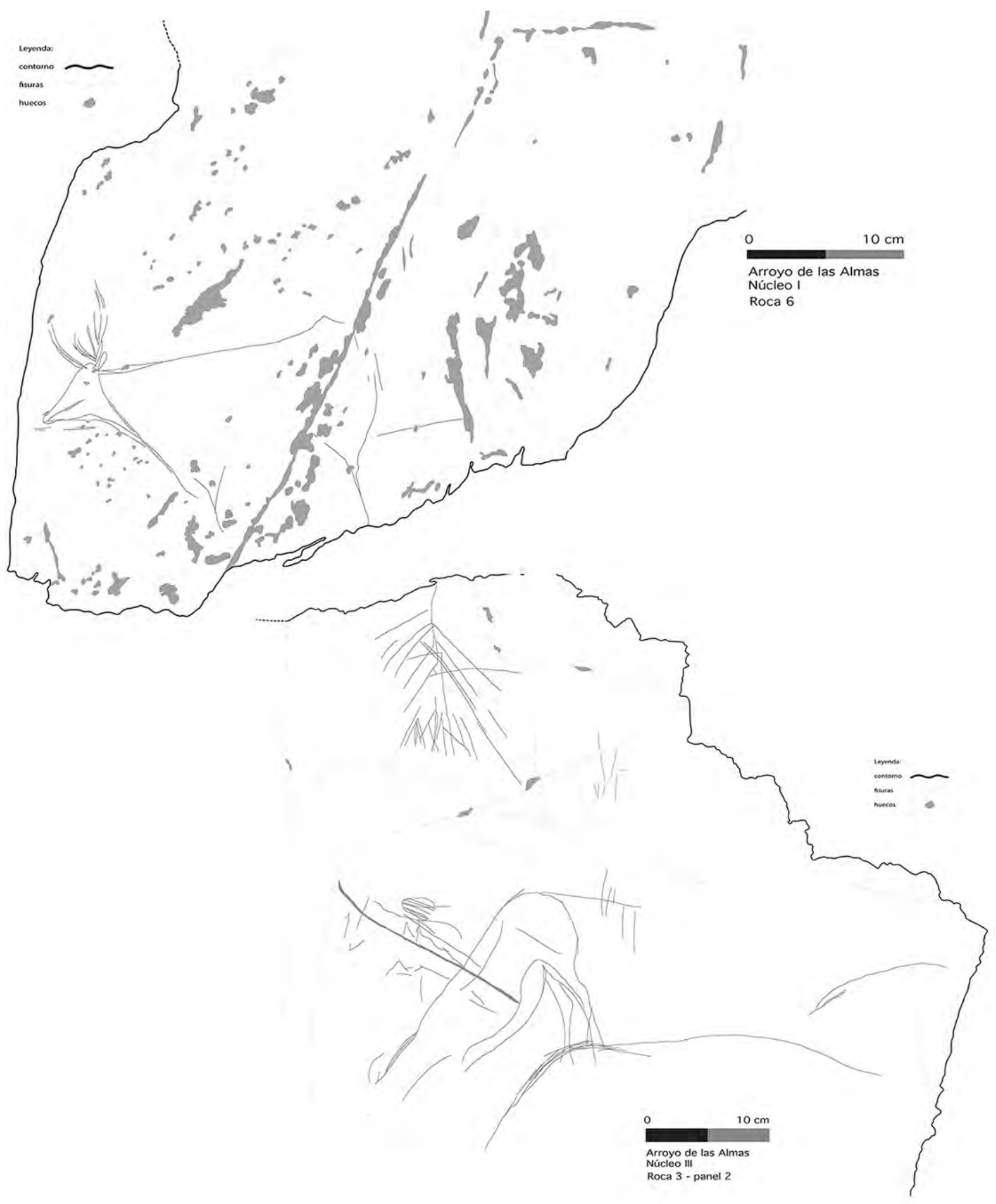

FIGURA 14. ARRIBA, CALCO PARCIAL DEL PANEL I DE LA ROCA 6 DEL NÚCLEO I DEL ARROYO DE LAS ALMAS. ABAJO, CALCO PARCIAL DEL PANEL 2 DE LA ROCA 3 DEL NÚCLEO IIIG 

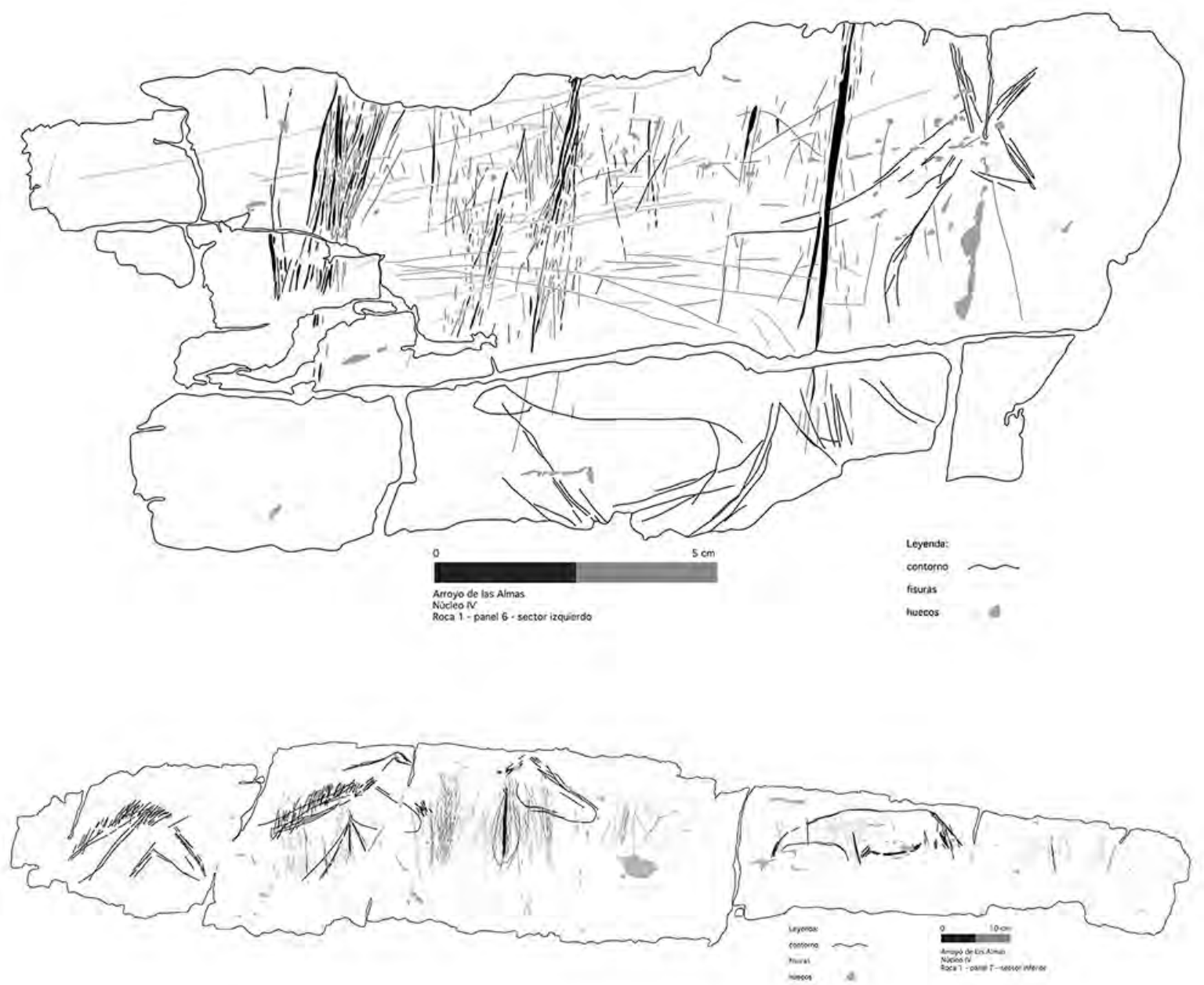

FIGURA 15. ROCA I DEL NÚCLEO IV DEL ARROYO DE LAS ALMAS. ARRIBA, CALCO PARCIAL DEL PANEL 6. ABAJO, CALCO PARCIAL DEL PANEL 7

varias líneas en trazos únicos, repetidos, continuos y discontinuos. El morro del animal también es diferente al de los otros prótomos de équidos del panel, Motivos i6 y I7, al tener una apuntada forma sin cerrar que llega hasta la grieta del panel. La línea cérvico-dorsal, ligeramente cóncava, también se ejecutó con grabados incisos únicos, repetidos y continuos.

Motivo 20. Prótomo incompleto de équido grabado mediante incisiones en trazos únicos, discontinuos y repetidos, y orientado hacia la derecha del observador, a Io cm del Motivo I7. Pese a las dificultades de observación, y su parcial ejecución, se perciben tanto la línea naso-frontal como la quijada convexa y el morro redondeado además del arranque de la crinera y varios posibles pelos hirsutos de su inicial crinera.

Motivo 2I. Representación zoomorfa acéfala grabada por incisión, en trazos únicos y repetidos, posiblemente un équido aunque inventariado como cuadrúpedo indeterminado, orientada a la izquierda, a más de $30 \mathrm{~cm}$ del Motivo 20. Se perciben tanto la línea cérvico-dorsal recta, que incluye la grupa, como los abundantes 
trazos utilizados para ejecutar el convexo vientre y simular la longitud del pelaje del animal, indicándose, en el tren delantero, el arranque de las extremidades anteriores sin completar. También ejecutaron el inicio de las extremidades posteriores y la cola como continuación de la línea cérvico-dorsal por abundantes trazos. Grabada en una peculiar posición inclinada, parece indicar que el animal se encuentra abrevando o comiendo. Impresión reforzada por su alargado cuellopecho, pudiendo tener crinera.
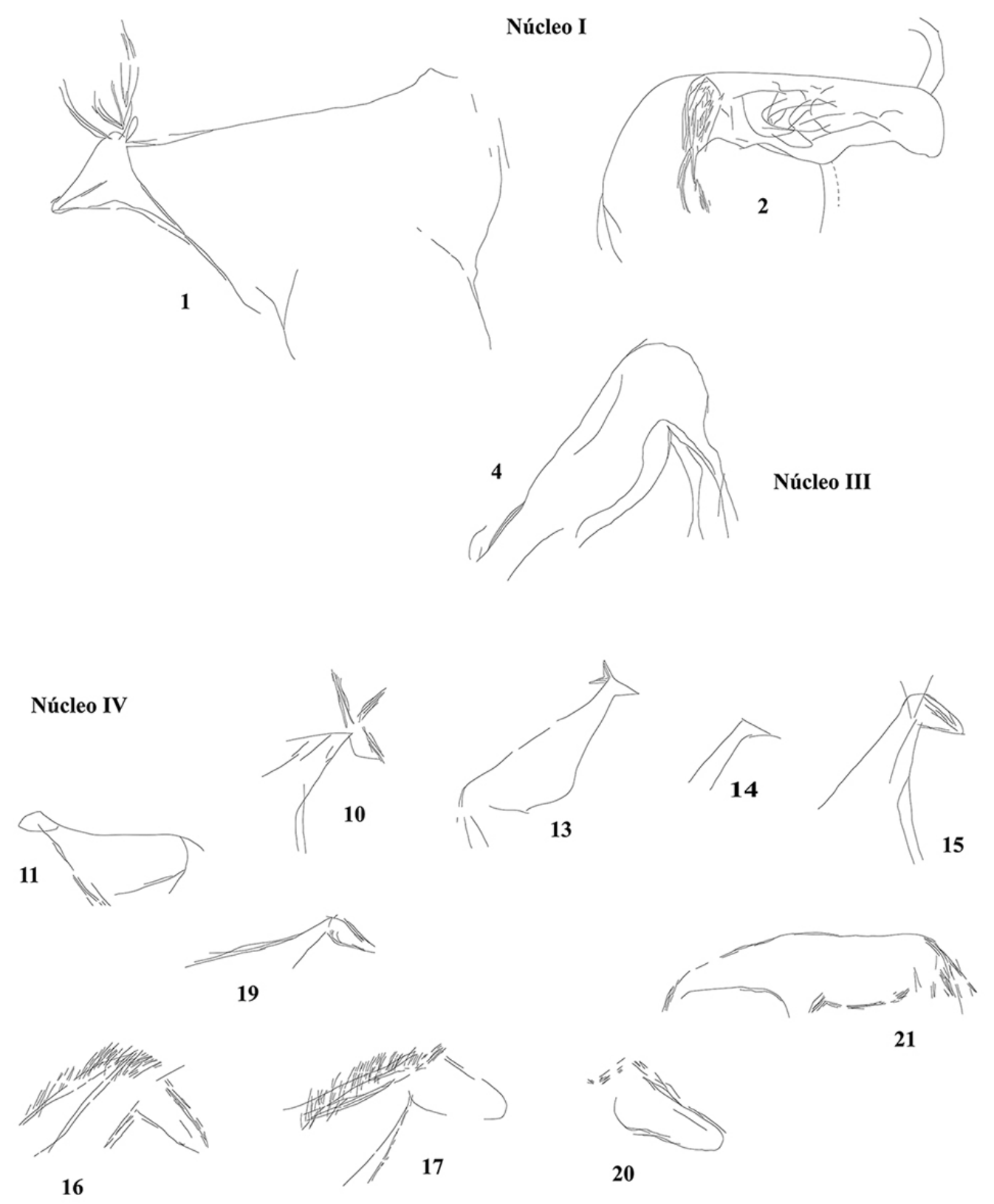

FIGURA 16. DETALLE DE LOS 13 MOTIVOS ZOOMORFOS DEL ARROYO DE LAS ALMAS 


\section{ANÁLISIS, VALORACIÓN Y PROPUESTA DE ADSCRIPCIÓN ESTILÍSTICA Y CRONOLÓGICA EN RELACIÓN CON OTROS CONJUNTOS RUPESTRES DE LA CUENCA DEL DUERO}

\subsection{BREVE ANÁLISIS SOBRE LOS CONJUNTOS DE TRAZOS NO FIGURATIVOS DEL ARROYO DE LAS ALMAS}

En el capítulo anterior, además de la descripción detallada de las figuras paleolíticas inventariadas, incluimos una descripción sumaria de los diversos conjuntos de trazos, o trazos aislados, localizados en todas las rocas paleolíticas de Arroyo de las Almas y qué por su aspecto, aparentemente informe y sin conexión, no consideramos motivos. Este tipo de agrupaciones de líneas son una constante en muchos sitios con arte rupestre, independientemente de su cronología, aunque particularmente relevantes en el arte paleolítico europeo, en todos sus ambientes y soportes. Releyendo diversas publicaciones sobre enclaves con manifestaciones paleolíticas, resulta que estas evidencias, más o menos caóticas y complejas, se muestran no solo frecuentes sino que habitualmente suelen acompañar a las figuras reconocibles, no siendo infrecuente que puedan aparecer como la única representación. Teniendo en cuenta, únicamente, los dos grandes conjuntos rupestres Paleolíticos más próximos al Arroyo de las Almas, Siega Verde y el valle del Côa, este mismo fenómeno acontece en muchas de sus rocas decoradas, siendo rara la superficie paleolítica, tanto con motivos piqueteados como incisos, especialmente en el conjunto portugués, que no presenta trazos aislados o conjuntos de trazos aparentemente inconexos (Santos 2017).

No es fácil hacer un análisis interpretativo sobre estos conjuntos de trazos. Quizá, porque la mente humana, y la científica en particular, busca orden y patrones reconocibles, existiendo una obvia dificultad en encajar dichos trazos caóticos en los patrones reconocidos sobre el arte Paleolítico. La ausencia de formas repetitivas e identificables nos impide incluirlos en el conjunto figurativo del arte Paleolítico, pero eso no significa que deban ser ignorados. En cuanto a las intenciones que puedan existir para su ejecución, son aun más complicadas de esclarecer que las de las otras representaciones. Es muy posible que algunos trazos puedan ser el resultado de errores o de pruebas previas llevadas a cabo con el instrumento de grabación, no siendo estrictamente necesario asignarles una intención simbólica. Sin embargo, por su cantidad y su sistemática y persistente presencia, se hace indefendible atribuirlas siempre al azar o a otras motivaciones accidentales. Por otro lado, no está nada claro en qué medida pueden, o no, ocupar un lugar semejante en la simbología paleolítica que tienen otras categorías temáticas. En otras palabras, ¿podrían las comunidades paleolíticas contemplar estos trazos como un tipo de figuras que obedecían a códigos reconocibles o somos nosotros los que no sabemos reconocer esos códigos? ¿Podría ser que no tenían el mismo sentido simbólico que las representaciones a las que llamamos «Figuras» o por el contrario podrían 
tener algún otro lugar en la simbología conjunta en una determinada superficie? La respuesta a estas preguntas no está clara.

La descripción llevada a cabo permite hacer un primer recuento de los conjuntos no figurativos que hemos reconocido. Sin embargo, nos parece más interesante hacer un primer análisis de carácter cualitativo, y no cuantitativo. Siendo Arroyo de las Almas un sitio pequeño y con pocas superficies decoradas, este análisis no permite avanzar demasiado en las interpretaciones sobre este tipo de representaciones aunque es, al menos, consistente. Únicamente han surgido algunas dudas en la asignación cronológica de los innumerables trazos de la roca I del Núcleo IV, especialmente en los paneles 6 y 7. Es posible que haya más conjuntos de trazos por reconocer, no estando completamente seguros de que todos deban ser considerados paleolíticos. Independientemente de estas dudas, podemos plasmar algunas ideas preliminares que hemos podido obtener tras observar el panorama general del Arroyo de las Almas.

En primer lugar, no parece haber ninguna estandarización cronológica que se pueda atribuir a la realización de estos trazos. En la larga diacronía que atribuimos al conjunto figurativo del Arroyo de las Almas, vemos que estos trazos inconexos acompañan a figuras con distintos estilos y fases cronológicas, desde los momentos iniciales, entre el Solutrense final y el Magdaleniense inicial, hasta el final del ciclo artístico Paleolítico. Esto encaja perfectamente con lo que se ha verificado en el valle del Côa, donde los conjuntos de trazos surgen acompañando a otras figuras desde el Gravetiense hasta el final del Magdaleniense.

Un segundo análisis es la reiteración en su ejecución. Las 5 rocas paleolíticas inventariadas los presentan, incluyendo una roca aparentemente poco importante como la roca ir del Núcleo I. Esto es un factor más que sugiere que estos trazos forman parte del repertorio gráfico que estas comunidades paleolíticas consideraron necesario ejecutar en las superficies que eligieron decorar.

Por último, y para complicar aun más nuestro análisis interpretativo, reseñar la heterogeneidad en las relaciones de estos trazos con las rocas en que se han documentado los motivos a los que se asocian. No debe ser por casualidad que la roca que más figuras presenta y que tiene la más larga diacronía figurativa, la roca I del Núcleo IV, es también la que más trazos inconexos tiene. Una roca que tiene una remarcable implantación en el paisaje del Arroyo de las Almas, y que consideramos importante en la interpretación funcional que atribuimos a este sitio. Por otro lado, las rocas 6, 7 y i del Núcleo I, ubicadas en uno de los macizos rocosos más perceptibles del valle del Arroyo de las Almas, presentan una cantidad relativamente reducida de estos trazos, hasta que en la oculta roca 3 del Núcleo III vuelven a aparecer en gran número, asociados a una notable figura zoomorfa y a los más complejos signos de todo el sitio.

Todo esto nos lleva a concluir que el papel de estos conjuntos de trazos en la simbología paleolítica podría ser, al igual que para el resto de la panoplia gráfica figurativa, mucho más complejo que lo que su aparente simplicidad sugiere. 


\subsection{EL CONJUNTO FIGURATIVO DEL ARROYO DE LAS ALMAS}

En la actualidad no existen datos precisos y objetivos que puedan ser utilizados para realizar asignaciones temporales fehacientes sobre la ejecución del conjunto gráfico Paleolítico del Arroyo de las Almas. Sin embargo, hasta que eso suceda, tanto en los temas abstractos como en los zoomorfos, el acercamiento, formal y técnico, teniendo en cuenta que esta aproximación nunca deberá ser considerada como indiscutible, es el único factible además de mostrarse, aun, como una variable esencial y nada desdeñable para entender la sociedad que ejecuta dichas manifestaciones (Rivero \& Sauvet 20I4).

Si atendemos a la contabilización total, 2I figuras, y su temática, percibimos un predominio de la categoría zoomorfa sobre la abstracta, aunque como ya hemos indicado, los problemas de identificación ligados al deficiente estado de conservación de alguno de los paneles catalogados y sus representaciones, podrían estar reflejando una realidad diferente y estar sobrevalorando los motivos de animales frente a los signos.

Este hecho, el predominio de una categoría sobre otra, es frecuente en los principales sitios con arte rupestre Paleolítico al aire libre de la cuenca del Duero, donde los animales son los motivos más documentados aunque la presencia de signos pueda ser proporcionalmente elevada en el caso de Siega Verde, con más del 30\% de las figuras inventariadas, de entre las que destacan tanto las formas ovales y semicirculares, realizados mediante piqueteado, paneles 2I, 3I o 75, como los reticulados incisos superpuestos a los zoomorfos piqueteados, panel i5, o los claviformes y barras, que también se ejecutan por piqueteado, en los paneles 46, 5I o 86 (Alcolea \& Balbín 2006: 80,89 , I20). Asimismo, aparecen otros motivos abstractos, especialmente lineales, panel 8 , ofreciendo relevantes analogías con varias cuevas del interior y del norte peninsular, y con la región artística del Côa y el propio Arroyo de las Almas en su Núcleo IV (Alcolea \& Balbín 2006: 254-260; Bueno et al. 2008).

En esta ya citada y cercana región artística portuguesa del valle del Côa no existe todavía una contabilización publicada sobre la totalidad de los signos paleolíticos, pero podemos afirmar, gracias a un trabajo reciente (Santos 20I7), y a otro trabajo en preparación, que son poco frecuentes en su fase más antigua, Graveto-Solutrense, aun existiendo algunos notables casos como en la roca I de Vale de Figueira (Baptista 2009: IIo). Sin embargo, en sus fases más recientes, aunque no sean tan abundantes como las figuras zoomorfas, en algunas rocas adquieren una gran importancia cuantitativa, como en la roca I4 de Foz do Côa, que tiene uno de los más importantes grupos de signos de todo el arte Magdaleniense del Côa. Pero es, sobre todo, en la fase final del Paleolítico superior donde los signos adquieren su mayor expresión, no muy distinta, desde el punto de vista cuantitativo, de las figuras zoomorfas, como en la roca i6 de Vale de José Esteves (Baptista 2009: II4-I29).

Destacar, además, que en el caso del Arroyo de las Almas tanto por sus numerosos signos ovales como por el gran signo de la roca 3 del Núcleo III (Motivo 5), con su peculiar organización interna, los paralelos son factibles con algunos de los signos identificados en los enclaves superopaleolíticos cavernarios más relevantes del continente europeo ya sean con los clásicos «tectiformes» del Périgord francés, o 
del territorio peninsular, como con los documentados en la categoría A.6 de la cueva del Castillo (Mingo 20I0: 234).

Otro de los rasgos que hemos observado, y factible de comparación a escala regional, que nos ofrece importantes pautas sobre la vinculación de este nuevo conjunto con su contexto artístico cercano, es la preeminencia, dentro la temática zoomorfa, de équidos y cérvidos: los animales más representados en el arte rupestre Paleolítico de la península ibérica. Otros importantes animales, desde la óptica cuantitativa, como los bovinos, ya sean uros o bisontes, están ausentes en el enclave rayano de Arroyo de las Almas, siendo la tercera especie más representada los caprinos. Un hecho un tanto extraño, ya que tanto en Siega Verde como en el valle del Côa los uros son animales frecuentes en sus distintas fases.

De entre los rasgos y atributos formales que tienen algunas de las figuras zoomorfas del Arroyo de las Almas, reseñar, por su incontestable valor para acercarnos a una datación relativa del conjunto y por su marcado carácter cronológico, los despieces advertidos en el Motivo 4. Una convención gráfica, en lo que se refiere a su atribución cronológica, asidua en el Magdaleniense peninsular, no solo al aire libre, y especialmente en su fase más reciente. Lo mismo sucede con el Motivo 2, en que la forma rectilínea del dorso y de la parte posterior, el uso del trazo repetido en el rellenado corporal y de las patas posteriores, además del característico subnaturalismo de la figura, sugieren una cronología tardía. No conocemos paralelos evidentes para el enmarañado que llena el cuerpo del animal, pero una de las figuras más destacables del arte mueble del sitio del Fariseu, en el valle del Côa, además de tratarse de un caprino con algunas semejanzas más, tiene un conjunto de rasgos en el interior del cuerpo conceptualmente similares a los que se encuentran en dicha figura (Aubry 2009: 387, 389). La cronología de esta placa, estratigráficamente insertada en una etapa transicional entre el Pleistoceno superior final y el Holoceno inicial, ayuda a corroborar nuestra propuesta. Señalar, asimismo, que al menos 4 de las figuras de animales documentadas se han representado completas, siendo alguno de ellos acéfalo (Motivo 4). Sin embargo, en los restantes 9 casos se reducen al prótomo del animal.

Todas las figuras documentadas ofrecen una total homogeneidad en lo referente a la técnica de grabado empleada: la incisión. Esto coincide plenamente con lo que ocurre en el arte parietal Paleolítico peninsular, donde la incisión es la modalidad preferentemente utilizada, aunque el piqueteado de contornos o la abrasión puedan tener un papel muy relevante en determinados enclaves, tanto cavernarios como abrigados o al aire libre. En lo tocante a las figuras de animales, existe alguna leve variación en cuanto a la modalidad empleada, como la observada en el Motivo 2, parcialmente ejecutada en trazo diferente, pero que de ninguna forma es la regla general del conjunto, ya que la mayoría de las figuras se llevaron a cabo delineando su contorno con un fino trazo único, qué en ocasiones, se vio reforzado en alguna parte del cuerpo, con dos o tres trazos repetidos. Además, todas ellas tienen reducidas dimensiones, al no superar ninguna figura los $30 \mathrm{~cm}$ de long. máx., siendo algunas extremadamente pequeñas, con apenas unos pocos cm (Tabla I).

El arte rupestre Paleolítico en estos tres núcleos del Arroyo de las Almas se inserta, claramente, desde el punto de vista formal y técnico, en la norma general del arte Paleolítico euroasiático, aunque, como es normal, los principales puntos de 
comparación acontecen en los conjuntos artísticos más cercanos y, sobre todo, en los conjuntos con arte Paleolítico de la cuenca del Duero, en la que se inserta este sitio. Así, los principales elementos de comparación que hemos utilizado para los motivos inventariados en el Arroyo de las Almas, surgen en los yacimientos vecinos del valle del Côa y de Siega Verde, a los que se une el más distante pero igualmente destacable complejo de Domingo García (Ripoll \& Municio I999; Balbín 2008: 2325; Rivero et al. 20I8). Importantes son también los tres enclaves con arte mueble de los ríos Côa y Sabor, donde se encuentran los yacimientos de Fariseu (Aubry 2009; Santos et al. 2018) y Cardina (Aubry et al. 2015) para el primero, y el recientemente descubierto gran conjunto de placas del sitio de Medal, en el segundo (Figueiredo et al. 2014, 2016).

Tras los análisis citados debemos recalcar, en primer lugar, la diacronía de este yacimiento donde la casi totalidad los motivos inventariados se encuadra en el Magdaleniense. Quizá, los primeros, entre el Solutrense final y el Magdaleniense inicial, con una datación que podría rondar los I80oo BP. Los últimos, por el contrario, se deberían situar en los momentos finales del Paleolítico superior, entre los 13000/12000 y 9000 BP (Vázquez Marcos 2019). Entre los primeros y los últimos, documentamos otras figuras, ejecutadas en momentos intermedios. Esto significa, si nuestra apreciación cronológica es correcta, que el yacimiento rupestre Paleolítico del Arroyo de las Almas tendría una vida de varios miles de años, que no deberá ser inferior a 6000 ni superior a 9000 años.

Hemos intentado recrear, con la inevitable incertidumbre connatural a un ejercicio de este género, lo que podría haber sido la evolución en la decoración del sitio del Arroyo de las Almas. Con base en esto, los primeros motivos del conjunto serían los 3 prótomos de équidos catalogados en la roca I del Núcleo IV, un friso de figuras tipológicamente idénticas, posiblemente ejecutadas de una vez y por una sola mano, en los momentos iniciales del Magdaleniense o finales del Solutrense. Esta roca congrega más de la mitad de los motivos inventariados en Arroyo de las Almas. Sin embargo, no es posible afirmar si las siguientes figuras en ser ejecutadas son también las de esta roca o las de otras de las inventariadas. A lo largo de las siguientes etapas del Magdaleniense se van a realizar otras figuras, tanto en esta roca del Núcleo IV (Motivos I3, I4, I5, I9 y 2I) como en la roca 6 del Núcleo I (Motivo I) o en la roca 3 del Núcleo III (Motivo 4). En estas dos últimas rocas, lo más probable es que la realización de las figuras referidas corresponda al mismo período que las restantes representaciones, en particular sus signos y conjuntos de líneas. En la roca I del Núcleo IV la ordenación cronológica de los signos y conjuntos de líneas es mucho más compleja aunque en algunos casos existen asociaciones entre estas y las figuras zoomorfas. Por último, ya en los momentos finales del Tardiglaciar e inicios del Holoceno, la roca I del Núcleo IV vuelve a ser decorada, en esta ocasión en un pequeño panel periférico, con los Motivos io y II. Es posible, aunque difícil de demostrar, que el motivo indeterminado de la roca i del Núcleo I (Motivo 3) sea también de este período final del Paleolítico superior. Asimismo, teniendo en cuenta las características estilísticas del Motivo 2, es posible que esta peculiar figura zoomorfa sea la última de las ejecutadas en este período, en la roca 7 del Núcleo I, una superficie situada a pocos metros del cérvido de la roca 6 y en el mismo 
contexto paisajístico del desfiladero rocoso que fluye hacia la rivera, pero con una probable separación temporal de varios miles de años, entre el inicio y el final en la decoración de este yacimiento Paleolítico.

\subsection{ARROYO DE LAS ALMAS: UNA POSIBLE INTERPRETACIÓN SOBRE EL ORIGEN DE SUS MOTIVOS PALEOLITTICOS}

Para terminar este capítulo, podemos obviar, momentáneamente, las consideraciones formales, técnicas y cronológicas sobre sus motivos paleolíticos e intentar especular sobre cuál pudo haber sido el lugar que ocupó en el paisaje simbólicamente marcado del valle del río Duero durante el Paleolítico superior. Desde luego, comparando las principales características del Arroyo de las Almas con el vecino complejo artístico del valle del Côa, destacan, por evidentes, sus similitudes paisajísticas. Independientemente de otras funciones y aportaciones que se puedan atribuir al segundo, es innegable que existe una relación entre su arte y la ocupación humana detectada en la zona final de este río, donde se conocen varias decenas de campamentos que probablemente se extendieron a lo largo y ancho de las terrazas fluviales que tiene, y tuvo, el Duero, durante el Pleistoceno superior final e inicios del Holoceno. Cierto es que la gran mayoría de estas últimas se encuentran, en la actualidad, sumergidas por las aguas de la albufera del embalse de Pocinho, siendo pocos los lugares de ocupación de este período conocidos a lo largo del Duero en las inmediaciones de la desembocadura del Côa (Aubry 2009).

Volviendo a la desembocadura del Águeda y al Arroyo de las Almas indicar que, hasta la fecha, no se conocen sitios de habitación con ocupación Paleolítica. Es muy probable que estos existieran, en las vastas terrazas fluviales junto a la desembocadura del Águeda, pero aun no han podido ser identificados. Un poco más arriba, sin embargo, en la margen portuguesa del Águeda y no lejos de la roca de Redor do Porco, se han identificado, recientemente, potenciales campamentos paleolíticos, que todavía están insuficientemente caracterizados (Baptista \& Reis 20II: I6).

A pesar de la proximidad entre río Águeda y el Côa, existe una clara separación geográfica entre los respectivos conjuntos de yacimientos rupestres. No podemos considerar por tanto los sitios rupestres, junto a la desembocadura del Águeda, como una mera continuación del complejo del Côa. Por otro lado, teniendo en cuenta el trabajo de investigación llevado a cabo en la zona final del río Águeda, tanto en la margen portuguesa, con el descubrimiento de la roca de Redor do Porco, como en la margen española, con el del Arroyo de las Almas, se puede afirmar que esta zona del Águeda no presenta ni una cantidad ni una densidad de sitios y rocas grabadas mínimamente comparable a las del Côa o Siega Verde. Es interesante resaltar que algo semejante sucede en el río Sabor, en Portugal, objeto de una reciente e intensa investigación arqueológica, al igual que en el Águeda; y muy cerca por tanto del río Côa, en un contexto paisajístico análogo y con pocos sitios con arte Paleolítico, destacando la terraza del Medal, con su extraordinaria colección de arte mueble (Figueiredo et al. 2014, 2016; Gaspar et al. 2015). 
Asimismo, se puede señalar una importante diferencia cualitativa entre los grandes complejos artísticos del Côa y Siega Verde, y quizás Domingo García, y los pequeños sitios como el de Arroyo de las Almas. Sería imprudente intentar generalizar determinadas interpretaciones para estos reducidos enclaves, ya que lo más probable es que obedezcan a diferentes motivaciones, debiéndose llevar a cabo, su análisis, caso por caso.

Para el sitio protagonista de este artículo hay una primera interpretación plausible, que emerge, rápidamente, cuando se mira el paisaje que lo rodea: su rivera es el acceso más fácil y evidente entre la desembocadura del Águeda y los páramos que la circundan. No es por casualidad que la carretera CL-5I7 discurra, en su final, paralela al arroyo. Se puede objetar que existen otras líneas de agua en las inmediaciones, que llevan a cabo este mismo trayecto, entre el fondo del valle y la parte más alta, con un desnivel positivo de al menos $300 \mathrm{~m}$. Sin embargo, ninguna ofrece las facilidades de acceso y tránsito de esta, que es el punto ideal para acceder, desde el final del Águeda y el Duero.

Así, y más allá del lenguaje simbólico y significados generales que se puedan atribuir al arte Paleolítico en su globalidad, sus rocas decoradas deberían ser interpretadas como un lenguaje gráfico específico del lugar, señalando un lugar de paso. Con respecto a esto, resulta interesante advertir que la roca i del Núcleo IV, la más importante y profusamente decorada del conjunto; un gran y destacado afloramiento en las inmediaciones de un pequeño afluente del principal arroyo, resulta fácilmente visible a partir de este, además de ser el último afloramiento importante en el paisaje del Arroyo de las Almas para quien desciende hacia la desembocadura del Águeda y del Duero. Un poco antes, habrían transitado por el desfiladero rocoso del Núcleo I, con las rocas 6, 7 y II, como el elemento paisajístico más destacado. Más difícil de encajar, en este planteamiento, es la roca 3 del Núcleo III, la primera que surge para quien desciende el Arroyo de las Almas, y escondida en el paisaje.

En otras palabras; y aceptando que el «vagabundeo» humano en tiempos prehistóricos a lo largo del valle se realizaría principalmente por el fondo, junto a la ribera, y no por la parte superior; los afloramientos decorados con grabados paleolíticos aparecen, en la mayor parte de las ocasiones, en implantaciones que destacan visualmente en el paisaje para los que transitan por el arroyo, exceptuando la mencionada roca. Incluso para esta, todo apunta a que pueda considerarse indirectamente rotulada en el paisaje, ya que aparece en las inmediaciones de la desembocadura de un pequeño afluente del Arroyo de las Almas, hito paisajístico evidente y fácilmente identificable. Finalmente, es importante señalar que los grabados paleolíticos del Arroyo de las Almas, sin embargo, no destacan en el paisaje. La técnica sustractiva utilizada; la incisión, y las reducidas dimensiones de todas las figuras, hacen que solo sean perceptibles visualmente desde una corta distancia. Su presencia, para los que conocen estas señales, está indicada por los lugares donde han sido colocadas, que solo se hacen evidentes caminando a lo largo de la orilla, desde donde es rápido y fácil acceder a los paneles decorados. 


\section{CONSIDERACIONES FINALES}

El descubrimiento del conjunto rupestre del Arroyo de las Almas no solo amplía el número de enclaves superopaleolíticos al aire libre en la península ibérica a más de 80 , una cifra que representa cerca del 30\% de los lugares con arte rupestre Paleolítico en este territorio, tanto en cueva, abrigo como al aire libre, sino que además, encuentra en él, otro nuevo y sólido pilar argumentativo para desechar la repetida idea, aun hoy, del arte Paleolítico a la intemperie como un fenómeno minoritario y marginal pese a los innumerables resultados arqueológicos obtenidos en los últimos años (Aubry 2015; Alcolea \& Balbín 2006, 2008; Bahn 2015; Balbín 2008; Baptista 1999, 2009; Collado 2006; Figueiredo et al. 2014, 2016; Garate et al. 20I6; Jordá Pardo et al. 1999; Ripoll \& Municio I999; Reis 2012, 2013, 2014; Sacchi 2008; Santos 2017; Santos et al. 2015, 2018; Teixeira \& Sanches 2017; Vázquez Marcos 20I7; Vázquez Marcos \& Angulo Cuesta 2019; Welker 2016).

Sobre este nuevo enclave, que contiene un reducido pero relevante conjunto gráfico con 2I figuras paleolíticas, además de abundantes grupos de trazos lineales difícilmente interpretables, queremos subrayar, e insistir, en el variado y diverso elenco de temas catalogados. Todos ellos ejecutados mediante la principal técnica de grabado sustractiva; la incisión, en varias de sus posibles modalidades.

De igual modo, mencionar sobre las figuras documentadas y sus principales caracteres formales, su atribución cronocultural tanto al Magdaleniense inicial y reciente, fase I para el sitio, como a los momentos finales del Tardiglaciar e inicios del Holoceno Temprano, o fase Il (Vázquez Marcos, 2019). Acaso, el magnífico ejemplar localizado en el Núcleo I (Motivo 4) y varios de los équidos del panel 7 de la roca I del Núcleo IV (Motivos I6, I7 y 20) podrían corresponder a un inicial momento premagdaleniense o transicional entre el Solutrense y el Magdaleniense, si consideramos algunos paralelos y convenciones como la disposición de las extremidades anteriores y posteriores y de los candiles, roseta y luchadera, tanto a escala regional como continental, de la primera de las figuras citadas, o la predominancia de prótomos sobre cuerpos completos y la escasez de rasgos y atributos anatómicos claramente descriptibles en varias de las figuras de équidos del panel 7 de la roca I del Núcleo IV (Vázquez Marcos \& Reis 20I9: I40, I4I, I44).

Como sinopsis de los datos ofrecidos y descritos a lo largo de esta propuesta sobre el arte más antiguo del Arroyo de las Almas, queremos insistir en su importante y enriquecedora contribución para reforzar la contrastada imagen de la existencia de contactos a corta y media distancia durante el Magdaleniense, en esta zona de la cuenca del río Duero (Santos, 20I7; Vázquez Marcos 20I7). Una red cultural de intercambios, perfectamente analizable de forma unitaria en su extremo oriental y occidental, que se muestra más cerrada y homogénea en momentos premagdalenienses y mucho más abierta y permeable con posterioridad, entre el final del Tardiglaciar y el inicio del Holoceno (Vázquez Marcos 2019). Ya que el sitio de Arroyo de las Almas no solo ratificaría lo antedicho, sino que abriría nuevas perspectivas en la investigación sobre el arte rupestre; preferentemente en la cuenca del Duero internacional al complementar los conocidos conjuntos al aire libre, y donde los futuros proyectos a desarrollar en este amplio territorio, simbólico 
y físico, deberían de ser pensados y elaborados no solo desde la movilidad de las sociedades humanas prehistóricas sino desde su sedentarización (Vázquez Marcos \& Angulo Cuesta 2019).

Su estratégica posición geográfica, en los intercambios culturales y de materias primas de los grupos humanos regionales, preferentemente en los momentos de mayor crecimiento demográfico, innovaciones tecnológicas y cambios medioambientales y su decoración, realizada a lo largo de varios miles de años, estaría relacionada con esta específica función como lugar de paso fundamental en esa red de permutas.

\section{FUENTES DE FINANCIACIÓN}

La prospección y posteriores investigaciones desarrolladas por los autores de este artículo, no recibieron concesión alguna de fondos provenientes de los sectores público, comercial o no lucrativo. 


\section{BIBLIOGRAFÍA}

Alcolea, J. J. \& Balbín, R. De. 2006: Arte Paleolítico al aire libre. El yacimiento rupestre de Siega Verde, Salamanca. Arqueología en Castilla y León. Memorias i6. Junta de Castilla y León.

Alcolea, J. J. \& BAlbín, R. DE. 2008: «El yacimiento rupestre de Siega Verde, Salamanca. Una visión de síntesis». En R. De Balbín (ed.): Arte prehistórico al aire libre en el sur de Europa. Junta de Castilla y León: 57-87.

Aubry, T. (ed.). 2009: 200 séculos da história do Vale do Côa: incursões na vida quotidiana dos caçadores-artistas do Paleolítico. Trabalhos de Arqueologia 52. IGESPAR. Lisboa.

Aubry, T. 2015: «Peuplement de l'intérieur de la Péninsule Ibérique pendant le Paléolithique supérieur: où en est-on?». ARPI o3 Extra. Homenaje a Rodrigo de Balbín Behrmann: 20-3I.

Aubry, T.; Barbosa, A. F.; Gameiro, C.; Luís, L.; Matias, H.; Santos, A. T. \& Silvestre, M. 2015: «De regresso à Cardina, I3 anos depois: resultados preliminares dos trabalhos arqueológicos de 20I4 no Vale do Côa». Revista Portuguesa de Arqueologia I8: 5-26.

BAHN, P. 20I5: «Open-air Ice Age art: the history and reluctant acceptance of an unexpected phenomenon». En P. Bueno y P. G. Bahn (eds): Prehistoric Art as Prehistoric Culture. Studies in Honour of Professor Rodrigo de Balbín-Behrmann. Archaeopress. Oxford: 79-92.

Balbín, R. De. (ed.). 2008: Arte Prehistórico al aire libre en el Sur de Europa. Serie Actas. Junta de Castilla y León.

BAptista, A. M. I999: No tempo sem tempo: A arte dos caçadores paleolíticos do Vale do Côa. Com uma perspectiva dos ciclos rupestres pós-glaciares. Parque Arqueológico do Vale do Côa/Centro Nacional de Arte Rupestre. Vila Nova de Foz Côa.

Baptista, A. M. 2009: O paradigma perdido. O Vale do Côa e a Arte Paleolítica de Ar Livre em Portugal. Afrontamento. Lisboa.

Baptista, A. M. 20i2: «El Arte Paleolítico en Portugal». En I. Escobar y B. Rodríguez (eds.): Arte sin artistas: una mirada al Paleolítico. Museo Arqueológico Regional. Alcalá de Henares. Madrid: 305-338.

Baptista, A. M. \& Reis, M. 20iı: «A rocha gravada de Redor do Porco. Um novo sítio com arte paleolítica de ar livre no rio Águeda (Escalhão, Figueira de Castelo Rodrigo)». Côavisão I3: I5-20.

Bueno, P.; Balbín, R. De. \& Alcolea, J. J. 2008: «Estilo V en el ámbito del Duero: Cazadores finiglaciares en Siega Verde (Salamanca)». En R. Balbín (ed.): Arte Prehistórico al aire libre en el Sur de Europa. Junta de Castilla y Léon: 259-286.

Collado, H. 2006: Arte rupestre en la cuenca del Guadiana: el conjunto de grabados del Molino Manzánez (Alconchel-Cheles). Memórias d’Odiana 4. Beja.

Fernández Moreno, J. J. \& Baptista, A. M. (eds.). 20Io: Siega Verde. Extensión del Valle del Côa: arte rupestre paleolítico al aire libre en la cuenca del Duero. Junta de Castilla y León.

Figueiredo, S.; Xavier, P.; Silva, A.; Neves, D. \& Domínguez, I. 20I4: «The Holocene transition and post-palaeolithic rock art from the Sabor Valley (Trás-os-Montes, Portugal)». En M. A. Medina-Alcaide, A. J. Romero Alonso, R. M. Ruiz-Márquez y J. L. Sanchidrián Torti (eds.): Sobre rocas y huesos: las sociedades prehistóricas y sus manifestaciones plásticas. Imprenta Luque: I93-203.

Figueiredo, S.; Nobre, L.; Xavier, P.; Gaspar, R. \& Carrondo, J. 20i6: «First approach to the chronological sequence of the engraved stone plaques of the Foz do Medal alluvial terrace in Trás-os-Montes, Portugal». ARPI 04 Extra. Homenaje a Rodrigo de Balbín Behrmann: 64-77. 
Garate, D.; Rios, J.; Pérez, R.; Rojas, R. \& Santonja, M. 2oi6: «Arte rupestre paleolítico al aire libre en el paraje de La Salud (valle del Tormes, Salamanca)». Zephyrus 77: 15-29.

Gaspar, R.; Ferreira, J., Molina, F. J.; García, F.; Rebelo, P. \& Neto, N. 20I5: «Away from the edges: a new Solutrean site in interior Iberia. Foz do Medal Left Bank, Sabor Valley, Northeast Portugal (NW Iberia)». Journal of Anthropological Research 71: 545-564.

JordÁ PARDo, J.; PASTOR, F. \& Ripoll, S. I999: «Arte rupestre paleolítico y postpaleolítico al aire libre en los Montes de Toledo occidentales (Toledo, Castilla-La Mancha): noticia preliminar». Zephyrus 52: 28I-296.

Mingo, A. 20io: Los signos rupestres del paleolítico: la cueva de El Castillo (Puente Viesgo, Cantabria). GEA Patrimonio.

ReIS, M. 20I2: «Mil rochas e tal...!: Inventário dos sítios da arte rupestre do vale do Côa». Portvgalia 33.: 5-72.

ReIS, M. 2013: «Mil rochas e tal...!: Inventário dos sítios da arte rupestre do vale do Côa ( $2^{\circ}$ parte)». Portvgalia 34: 5-68.

ReIS, M. 20I4: «Mil rochas e tal...: Inventario dos sítios da arte rupestre do vale do Côa (conclusão)». Portvgalia 35: 17-59.

ReIS, M. \& VÁzqueZ Marcos, C. 20I5: «Arte rupestre en la frontera hispano-portuguesa: cuenca del río Águeda». ARPI 03 Extra. Homenaje a Rodrigo de Balbín Behrmann:32-43.

Reis, M. \& VÁzquez Marcos, C. 2oIg: «Arroyo de las Almas (La Fregeneda, Salamanca): un nuevo conjunto con arte rupestre en la cuenca del Duero». Complutum 30 (2): 223-245.

Ripoll, S. \& Municio, L. (eds.): I999: Domingo García. Arte Rupestre Paleolítico al aire libre en la meseta castellana. Arqueología en Castilla y León. Memorias 8. Junta de Castilla y León.

Rivero, O. \& SAUvet, G. 20I4: «Defining Magdalenian cultural groups in Franco-Cantabria by the formal analysis of portable artworks». Antiquity 88. 339: 64-80.

Rivero, O.; Ruiz, J.F.; Ortega, P.; Salazar, S.; Intxaurbe, l. \& Bustos, P. 20i8: Estudio, documentación y restitución del arte parietal del yacimiento del Cerro de San Isidro (Domingo García, Segovia). Informe de la actuación en el yacimiento del Cerro de san Isidro (Domingo García, Segovia).

SACCHI, D. 2008: «Le rocher gravé de Fornols vingt trois ans après sa découverte». En R. Balbín (ed.): Arte prehistórico al aire libre en el Sur de Europa. Junta de Castilla y León: 193-209.

SAntos, A. T. 20I2: «Reflexões sobre a arte Paleolítica do Côa: a propósito da superação de uma persistente dicotomia conceptual». En M. J. Sanches (ed.): $I^{a}$ Mesa-Redonda Artes Rupestres da Pré-História e da Proto-História: Paradigmas e Metodologias de Registo. Trabalhos de Arqueologia 54. DGPC. Lisboa: 39-67.

SANTos, A. T. P. S. C. 20I7: A arte paleolítica ao ar livre da bacia do Douro à margem direita do Tejo: uma visão de conjunto. Tesis doctoral, Universidad de Porto.

Santos, A. T.; Sanches, M. J. \& Teixeira, J. C. 20I5: «The Upper Palaeolithic rock art of Portugal in its Iberian context». En P. Bueno y P. G. Bahn (eds): Prehistoric Art as Prehistoric Culture. Studies in Honour of Professor Rodrigo de Balbín-Behrmann. Archaeopress. Oxford: I23-I34.

Santos, A. T.; Aubry, Th.; Barbosa, A. F.; García, M. \& Sampaio, J. D. 20i8. «O final do ciclo gráfico paleolítico do Vale do Co^a: A arte móvel do Fariseu (Muxagata, Vila Nova Foz Côa)». Portvgalia 39: 5-96.

Teixeira, J. C. \& Sanches, M. J. 20I7: «O abrigo rupestre da foz do rio Tua no contexto da arte paleolítica e pós-paleolítica do Noroeste da Península Ibérica». Portvgalia 38: 9-48. 
Vázquez Marcos, C. 20I4: «Análisis estadístico del caballo en el sitio de Siega Verde». En M. S. Corchón y M. Menéndez (eds.): Cien años de arte rupestre paleolítico. Universidad de Salamanca: 273-283.

VÁzQUeZ MARCos, C. 20I5: «Análisis estadístico de las grafías figurativas zoomorfas de cabras grabadas en el sitio arqueológico de Siega Verde (Serranillo, Salamanca, España)». En H. Collado y J. G. Arranz (eds.): Actas del XIX International Rock Art Conference. IFRAO. ARKEOS 37. Cáceres: 847-862.

VÁzQuez Marcos, C. 20I7: «Despieces ventrales 'en M' en las representaciones peninsulares de équidos superopaleolíticos». Sautuola XIX: 47I-500.

Vázquez Marcos, C. 2018: «El arte Paleolítico de Siega Verde (Serranillo, Salamanca, España): Una sintética visión en el trigésimo aniversario de su descubrimiento». Estudos do Quaternário i9: 63-82.

VÁzquez Marcos, C. 20I9: «El final del ciclo gráfico Paleolítico en la península lbérica sobre soportes parietales». En G. García Atiénzar \& V. Braciela González (Coords.). Sociedades prehistóricas y manifestaciones artísticas. Imágenes, nuevas propuestas e interpretaciones. INAPH. Colección Petracos 2: 87-92.

Vázquez Marcos, C. \& Reis, M. 20I9: «Arroyo de las Almas (La Fregeneda, Salamanca): un nuevo sitio con arte Paleolítico al aire libre». Trabajos de Prehistoria 76 (I): I38-I46.

Vázquez Marcos, C. \& Angulo Cuesta, J. 20ig: Conoce Siega Verde. Arte Paleolítico al aire libre. Centro de Estudios Mirobrigenses y Excmo. Ayuntamiento de Ciudad Rodrigo. Trabajos de investigación, I2.

WelKER, W. 20I6: «First Palaeolithic rock art in Germany: engravings on Hunsrück slate». Antiquity 90 (349): 32-47. 



\section{Artículos · Articles}

ÁNGEL RIVERA ARRIZABALAGA

Numerical Abstraction in Prehistory. A View from Cognitive Archeology . Abstracción numérica en la Prehistoria. Una visión desde la arqueología cognitiva

líticos - Technical Mode 3 Site of the Ancient Fábrica de Conservas Garavilla. Technological Analysis of Lithic Support

Lugar de paso, memorias antiguas. El yacimiento del Arroyo de las Almas (La Fregeneda, Salamanca) y su arte rupestre Paleolítico al aire libre. Place of Passage, Ancient Memories. The Site of Arroyo de las Almas (La Fregeneda, Salamanca) and its Open-Air Palaeolithic Rock Art

105 José Iganacio Royo Guillén, Francisco josé Navarro Cabeza y Serafín Benedí Monge

Un paisaje sacralizado por grabados rupestres protohistóricos e históricos en las hoces del río Mesa (Calmarza, Zaragoza) .

A Sacralized Landscape by Protohistoric and Historical Rock Engravings in the Gorges of the River Mesa (Calmarza, Zaragoza)

Noemí Raposo GutiérRez

Delimitación de los espacios públicos en el Pagus Augustus Felix Suburbanus. Necrópolis de Porta Ercolano (Pompeya-Italia) ·

The delimitation of the public spaces in the Pagus Augustus Felix Suburbanus. Necropolis of Ercolano Gate (Pompeii-Italy)

TERESA BUEy UTRILLA

Soportes epigráficos y promoción social: mujeres libertas promotoras de monumentos honoríficos en Tarraco · Epigraphic Media and Social Promotion: Freedwomen Sponsorhip of Honorific Monuments in Tarraco

IRENE SALINERo SÁNCHEZ

El Tesorillo (Teba), Eras de Peñarrubia y Plataforma de Peñarrubia (Campillos), implantación, particularidades y semejanzas de tres necrópolis tardoantiguas · El Tesorillo (Teba), Eras de Peñarrubia y Plataforma de Peñarrubia (Campillos), Implementation, Particularities and Similarities of Three Necropolis of Late Antiquity

\section{GUILLERMO LUIS LóPEZ MERINO}

El Historicismo en la Restauración Arquitectónica: el ejemplo del Alcázar de los Reyes Cristianos de Córdoba · Historicism in Architectural Restoration: The Example of the Alcázar of the Christian Kings of Cordova

\section{Reseñas • Books Review}

239 Alba García-Álvarez

FINLAYSON, Clive: El Neandertal Inteligente. Arte rupestre, captura de aves y revolución cognitiva, Córdoba, Editorial Almuzara, 2020, 253 pp., ISBN: 978-84-18089-53-4.

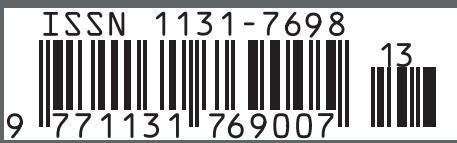

